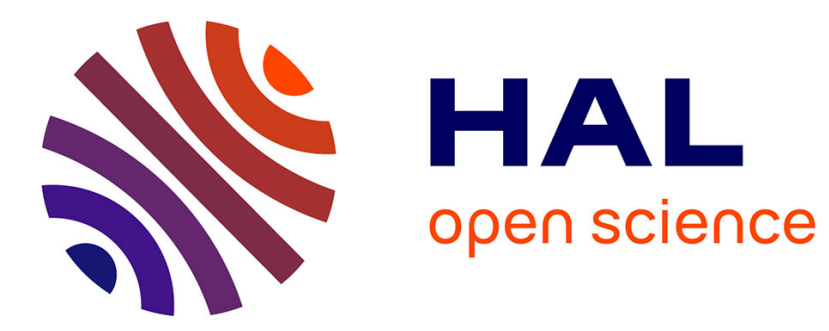

\title{
Quantifying Carbon Cycle Feedbacks
}

\author{
J. Gregory, C. Jones, P. Cadule, P. Friedlingstein
}

\section{To cite this version:}

J. Gregory, C. Jones, P. Cadule, P. Friedlingstein. Quantifying Carbon Cycle Feedbacks. Journal of Climate, 2009, 22 (19), pp.5232-5250. 10.1175/2009JCLI2949.1 . hal-03197002

\section{HAL Id: hal-03197002 https://hal.science/hal-03197002}

Submitted on 15 Apr 2021

HAL is a multi-disciplinary open access archive for the deposit and dissemination of scientific research documents, whether they are published or not. The documents may come from teaching and research institutions in France or abroad, or from public or private research centers.
L'archive ouverte pluridisciplinaire HAL, est destinée au dépôt et à la diffusion de documents scientifiques de niveau recherche, publiés ou non, émanant des établissements d'enseignement et de recherche français ou étrangers, des laboratoires publics ou privés. 


\title{
Quantifying Carbon Cycle Feedbacks
}

\author{
J. M. GREGORY \\ Walker Institute for Climate System Research, University of Reading, Reading, and Met Office Hadley Centre, \\ Exeter, United Kingdom \\ C. D. JONES \\ Met Office Hadley Centre, Exeter, United Kingdom \\ P. CADUle \\ CNRS/IPSL, Paris, and IPSL/LSCE, Gif-sur-Yvette, France \\ P. FRIEDLINGSTEIN \\ IPSL/LSCE, Gif-sur-Yvette, France, and QUEST, University of Bristol, Bristol, United Kingdom
}

(Manuscript received 24 November 2008, in final form 17 April 2009)

\begin{abstract}
Perturbations to the carbon cycle could constitute large feedbacks on future changes in atmospheric $\mathrm{CO}_{2}$ concentration and climate. This paper demonstrates how carbon cycle feedback can be expressed in formally similar ways to climate feedback, and thus compares their magnitudes. The carbon cycle gives rise to two climate feedback terms: the concentration-carbon feedback, resulting from the uptake of carbon by land and ocean as a biogeochemical response to the atmospheric $\mathrm{CO}_{2}$ concentration, and the climate-carbon feedback, resulting from the effect of climate change on carbon fluxes. In the earth system models of the Coupled Climate-Carbon Cycle Model Intercomparison Project (C4MIP), climate-carbon feedback on warming is positive and of a similar size to the cloud feedback. The concentration-carbon feedback is negative; it has generally received less attention in the literature, but in magnitude it is 4 times larger than the climate-carbon feedback and more uncertain. The concentration-carbon feedback is the dominant uncertainty in the allowable $\mathrm{CO}_{2}$ emissions that are consistent with a given $\mathrm{CO}_{2}$ concentration scenario. In modeling the climate response to a scenario of $\mathrm{CO}_{2}$ emissions, the net carbon cycle feedback is of comparable size and uncertainty to the noncarbon-climate response. To quantify simulated carbon cycle feedbacks satisfactorily, a radiatively coupled experiment is needed, in addition to the fully coupled and biogeochemically coupled experiments, which are referred to as coupled and uncoupled in C4MIP. The concentration-carbon and climate-carbon feedbacks do not combine linearly, and the concentration-carbon feedback is dependent on scenario and time.
\end{abstract}

\section{Introduction}

During coming decades and centuries, climate change is expected in response to anthropogenic emissions into the atmosphere, especially of carbon dioxide. Projections of global climate change, for instance as assessed by Meehl et al. (2007) for the Intergovernmental Panel

Corresponding author address: Jonathan Gregory, P.O. Box 243, Meteorology Building, University of Reading, Reading, RG6 6BB, United Kingdom.

E-mail: j.m.gregory@reading.ac.uk on Climate Change, are based principally on the results of three-dimensional atmosphere-ocean general circulation models (AOGCMs), which simulate relevant dynamical and physical processes at a horizontal resolution typically of $2^{\circ}-3^{\circ}$. Despite the complexity of the system, model results indicate that its global-mean behavior can be described in rather simple terms as linear responses and feedbacks. The resulting conceptual framework is useful for comparison of the models with one another and the real world.

In recent years, increasing attention has been paid to the possible responses of terrestrial ecosystems and 
TABLE 1. Notation and units for main quantities discussed. Note that $C$ is often given in ppm and $\beta$ in $\mathrm{GtC}_{\mathrm{ppm}}{ }^{-1}: 1 \mathrm{GtC}^{\mathrm{gt}} \equiv 0.47 \mathrm{ppm}$ of $C$. Following electronics literature, the terms gain factor and feedback factor (both dimensionless) are sometimes used the other way round (Roe and Baker 2007); however, feedback parameter $\left(\mathrm{W} \mathrm{m}^{-2} \mathrm{~K}^{-1}\right)$ is unambiguous.

\begin{tabular}{|c|c|c|}
\hline$F_{(C, N)}$ & $\mathrm{W} \mathrm{m} \mathrm{m}^{-2}$ & Radiative forcing ( $C, N$ indicating forcing from $\mathrm{CO}_{2}$ or non- $\mathrm{CO}_{2}$ agents) \\
\hline$F_{2 \times}$ & $\mathrm{W} \mathrm{m} \mathrm{m}^{-2}$ & $F$ resulting from doubling of atmospheric $\mathrm{CO}_{2}$ \\
\hline$T$ & $\mathrm{~K}$ & Global-mean surface air temperature change wrt unperturbed state \\
\hline$T_{\mathrm{BB}}$ & $\mathrm{K}$ & $T$, if there was only the blackbody response \\
\hline$T_{n \gamma}$ & $\mathrm{K}$ & $T$ with all feedbacks except climate-carbon \\
\hline$T_{2 \times}$ & $\mathrm{K}$ & Equilibrium climate sensitivity \\
\hline$\lambda_{(i)}$ & $\mathrm{W} \mathrm{m}^{-2} \mathrm{~K}^{-1}$ & $\begin{array}{l}\text { Climate feedback parameter (with components } i \text {, including blackbody } \\
\lambda_{0}=\lambda_{\mathrm{BB}} \text {, but not including } r_{\beta}, r_{\gamma} \text { ) }\end{array}$ \\
\hline$y$ & $\mathrm{~W} \mathrm{~m}^{-2} \mathrm{~K}^{-1}$ & $-\sum_{i>0} \lambda_{i}($ positive $y$ gives positive feedback on $T$ ) \\
\hline$\kappa$ & $\mathrm{W} \mathrm{m}{ }^{-2} \mathrm{~K}^{-1}$ & Ocean heat uptake efficiency \\
\hline$\rho$ & $\mathrm{W} \mathrm{m}{ }^{-2} \mathrm{~K}^{-1}$ & $\begin{array}{l}\text { Climate resistance, the sum of the climate feedback parameter } \\
\text { and the ocean heat uptake efficiency }\end{array}$ \\
\hline$r_{\beta}, r_{\gamma}$ & $\mathrm{W} \mathrm{m}^{-2} \mathrm{~K}^{-1}$ & $\begin{array}{l}\text { Additional climate feedback parameters resulting from the concentration-carbon } \\
\text { and climate-carbon responses to } \mathrm{CO}_{2} \text { emissions }\end{array}$ \\
\hline$C_{E}$ & $\mathrm{GtC}$ & Emitted carbon \\
\hline$C$ & $\mathrm{GtC}$ & Change in carbon content of atmosphere with respect to unperturbed state \\
\hline$C_{n \gamma}$ & GtC & $\mathrm{C}$ in response to $\mathrm{CO}_{2}$ emissions with all feedbacks included except climate-carbon \\
\hline$\phi$ & $\mathrm{W} \mathrm{m}^{-2} \mathrm{GtC}^{-1}$ & Derivative of $F_{C}$ with respect to $C$ \\
\hline$\gamma$ & $\mathrm{GtC} \mathrm{K}^{-1}$ & Sensitivity of land and ocean carbon storage to $T$ \\
\hline$\beta$ & 1 & Sensitivity of land and ocean carbon storage to $C$ \\
\hline$u_{(i)}$ & 1 & Carbon response parameter (with components $i$, including $u_{0}=1$ for atmospheric $C$ ) \\
\hline$u_{\gamma}$ & 1 & Climate-carbon response parameter (contribution to $u$ ) \\
\hline$g_{T}, g_{C}, g_{\mathrm{CC}}$ & 1 & Climate, carbon, and climate-carbon gain factors \\
\hline$G_{T}, G_{\mathrm{CC}}$ & 1 & $\begin{array}{l}\text { Climate and climate-carbon feedback factors (note that } A \text { is the carbon } \\
\text { feedback factor corresponding to } g_{C} \text { ) }\end{array}$ \\
\hline$A$ & 1 & Incremental or cumulative airborne fraction of emitted carbon \\
\hline
\end{tabular}

ocean biogeochemistry to increasing atmospheric $\mathrm{CO}_{2}$ concentration and the consequent climate change. Perturbations to the carbon cycle will change the storage of carbon on land and in the ocean, constituting a feedback on the atmospheric $\mathrm{CO}_{2}$ concentration. Because of their potential importance for future climate change, representations of the relevant processes are being incorporated into AOGCMs. Simulated carbon cycle changes exhibit a large spread, indicating systematic uncertainty in the models (Friedlingstein et al. 2006; Meehl et al. 2007; Plattner et al. 2008). As with the physical climate system, model comparison may identify the sources of uncertainty and help to reduce it. Simple global-mean metrics are useful for this purpose.

It appears to us that there are important analogies between the responses of the carbon cycle and the climate to forcing, but the ways in which they are described in recent literature are rather different, and this obscures the similarity and makes comparison difficult. The first aim of the present paper is to present and relate various conceptual frameworks. We show how the magnitude of carbon cycle and climate feedbacks can be compared directly by putting them into the same terms. (For convenience we have summarized the notation in Table 1 and the main results in Table 2.) We then illustrate the use of these metrics in studying past and future changes, and we discuss shortcomings and improvements.

\section{Climate change and feedback}

In this section, we review the formalism used to quantify climate feedback, which we will compare in subsequent sections with carbon cycle feedback; Roe (2009) provides a useful and more detailed account of feedback formalism. Changes in composition of the atmosphere from anthropogenic emissions of greenhouse gases and aerosols primarily have their climatic effect through perturbing the heat balance of the climate system. Their influence is measured in terms of their radiative forcing $F\left(\mathrm{~W} \mathrm{~m}^{-2}\right)$. To be stable to radiative perturbations, the climate system must tend to resist $F$ with an opposing radiative response $H$, which is the increase resulting from climate change in the global-mean rate of heat loss to space by the system. The net heat flux into the system is thus $N=F-H$. On multiannual time scales, the net downward radiative flux at the top of the atmosphere and the net heat flux into the ocean are practically equal definitions of $N$, because nearly all of the heat capacity resides in the ocean. Climate change evolves while $N \neq 0$ on a time scale determined by this thermal inertia. 
TABLE 2. Summary of main results for climate and carbon response and feedbacks. References are to equation numbers in the text. These formulas apply to time-dependent change in which constant ocean heat uptake efficiency $\kappa$ is a good approximation.

Heat balance (resistance form)

Measure of climate response to radiative forcing

Climate feedbacks on $T$ (gain form)

Heat balance modified to include ocean heat uptake and carbon cycle feedback for $\mathrm{CO}_{2}$ emissions

Carbon balance (resistance form) for $\mathrm{CO}_{2}$ emissions

Measure of $\mathrm{CO}_{2}$ response to emissions

Carbon feedbacks on $C$ (gain form) for $\mathrm{CO}_{2}$ emissions

Climate-carbon feedback (gain form) on the $C, T$, which would result from $\mathrm{CO}_{2}$ emissions in the absence of this feedback

$$
\begin{aligned}
F & =\lambda T \text { and } \lambda=T \sum_{i} \lambda_{i} \\
T_{2 \times} & =\frac{F_{2 \times}}{\lambda}=\frac{F_{2 \times}}{\sum_{i} \lambda_{i}} \\
G_{T} & =\frac{T}{T_{\mathrm{BB}}}=\frac{1}{1-g_{T}}, \quad g_{T}=\sum_{i>0} \frac{-\lambda_{i}}{\lambda_{\mathrm{BB}}}, \quad \text { and } \\
T_{\mathrm{BB}} & =\frac{F}{\lambda_{\mathrm{BB}}} \\
F_{C}\left(C_{E}\right) & =T\left(\rho+r_{\beta}+r_{\gamma}\right), \\
\rho & =\lambda+\kappa, \quad r_{\beta}=\rho \beta, \quad \text { and } r_{\gamma}=\phi \gamma \\
C_{E} & =u C, \quad u=\sum_{i} u_{i}=1+\beta+u_{\gamma}, \quad \text { and } \\
u_{\gamma} & =\frac{\phi \gamma}{\rho} \quad{ }^{\prime} \quad u_{i} \\
A & =\frac{C}{C_{E}}=\frac{1}{u}=\frac{1}{\sum_{i}} \\
A & =\frac{C}{C_{E}}=\frac{1}{1-g_{C}} \text { and } g_{C}=-\sum_{i>0} u_{i} \\
C, T & =G_{\mathrm{CC}} C_{n \gamma}, T_{n \gamma}, \quad G_{\mathrm{CC}}=\frac{1}{1-g_{\mathrm{CC}}}, \quad \text { and } \\
g_{\mathrm{CC}} & =-\frac{u_{\gamma}}{1+\beta}=-\frac{\phi \gamma}{\lambda(1+\beta)}
\end{aligned}
$$

A new steady state in equilibrium with the forcing is attained when $N=0 \Rightarrow H=F$. If the climate system behaved like a blackbody, the system would warm up by enough to compensate for the forcing, according to the Stefan-Boltzmann law. The anthropogenic forcings of relevance to coming centuries would produce globalmean temperature changes of a few kelvins. Because this is small compared with the global-mean temperature of about $255 \mathrm{~K}$ required to balance solar irradiance, the blackbody response can be linearized as $H_{\mathrm{BB}}=\lambda_{\mathrm{BB}} T$, with $\lambda_{\mathrm{BB}}=4 \sigma_{\mathrm{SB}} 255^{3}=3.8 \mathrm{~W} \mathrm{~m}^{-2} \mathrm{~K}^{-1}$, where $T$ is the change in global-mean temperature with respect to the unperturbed climate, and $\sigma_{\mathrm{SB}}$ is the Stefan-Boltzmann constant (Hansen et al. 1984).

Results from climate models and analyses of observations confirm a linear relationship $H=\lambda T$ (e.g., Gregory et al. 2004), but $\lambda<\lambda_{\mathrm{BB}}$; that is, the climate warms up by more than would be expected from the blackbody response. For example, Dufresne and Bony (2008) give a mean $\lambda$ of $1.3 \mathrm{~W} \mathrm{~m}^{-2} \mathrm{~K}^{-1}$ and a standard deviation of $0.3 \mathrm{~W} \mathrm{~m}^{-2} \mathrm{~K}^{-1}$ from a set of recent AOGCMs. The constant $\lambda$ is the climate feedback parameter. The equilibrium climate sensitivity $T_{2 \times}$ is defined as the steady-state $T$ for a doubling of the atmospheric $\mathrm{CO}_{2}$ concentration; if the radiative forcing resulting from $2 \times \mathrm{CO}_{2}$ is $F_{2 \times}$, then

$$
T_{2 \times}=\frac{F_{2 \times}}{\lambda} .
$$

Taking $F_{2 \times}=3.7 \mathrm{~W} \mathrm{~m}^{-2}$ [as indicated by Myhre et al. (1998) and the mean of AOGCMs reported by Forster and Taylor (2006)], the blackbody response alone would give $T_{2 \times}=1.0 \mathrm{~K}$, but AOGCMs, historical records, and proxy climate evidence indicate that $T_{2 \times}$ is likely to lie in the range of 2.0-4.5 K (Meehl et al. 2007).

The reason for the difference between $\lambda$ and $\lambda_{\mathrm{BB}}$ is that various aspects of the climate change that develops affect the radiative balance; that is, they alter $H$. Those usually identified are from changes in water vapor (WV), tropospheric lapse rate (LR), surface albedo resulting from ice and snow, and cloud (Hansen et al. 1984; Colman 2003; Randall et al. 2007). Models suggest that their radiative effects are separately proportional to $T$ (Gregory and Webb 2008). Hence, in a steady state,

$$
\begin{aligned}
F & =H=\lambda T \\
& =T\left(\lambda_{\mathrm{BB}}+\lambda_{\mathrm{WV}}+\lambda_{\mathrm{LR}}+\lambda_{\text {albedo }}+\lambda_{\text {cloud }}+\cdots\right) .
\end{aligned}
$$

The net effect of the nonblackbody terms is to reduce $\lambda$, and hence increase the steady-state $T=F / \lambda$. For instance, $\lambda_{\mathrm{WV}}<0$, because rising $T$ leads to greater humidity, and because water vapor is a greenhouse gas, this inhibits heat loss by the climate system. Likewise, $\lambda_{\text {albedo }}<0$ because higher $T$ reduces the area covered by ice and snow, reducing the surface albedo and leading to greater absorption of sunlight. Cloud changes have for many years been the greatest source of uncertainty in $\lambda$; 
their net effect might be of either sign (Randall et al. 2007; Soden et al. 2008).

The original interpretation of the heat balance, which we refer to as the gain interpretation, regards the blackbody response as basic, or leading to a basic temperature response $F / \lambda_{\mathrm{BB}}$. In the gain interpretation the modifications to $H$ by the other processes augment the $F$ that is being resisted by the blackbody response; thus,

$$
\lambda_{\mathrm{BB}} T=F+\sum_{i \neq \mathrm{BB}}\left(-\lambda_{i} T\right) .
$$

This rearrangement of the heat balance is the reason why the nonblackbody effects are usually called feedbacks; they feed back on $T$ by modifying $F$.

Let us number the contributions to $\lambda$ as $i=0,1, \ldots$. We designate $\lambda_{\mathrm{BB}}$ as $\lambda_{0}$. With the feedback idea, it is natural to write $y_{i} \equiv-\lambda_{i}$ for $i>0$, because positive $y_{i}$ means positive feedback. Positive feedbacks are those which increase $T$ for a positive $F$, for example, water vapor feedback $y_{\mathrm{Wv}}=-\lambda_{\mathrm{Wv}}>0$. Then,

$$
\begin{aligned}
\lambda_{0} T & =F+\sum_{i>0} y_{i} T \Rightarrow F=T\left(\lambda_{0}-y\right), \\
y & =\sum_{i>0} y_{i}=-\sum_{i>0} \lambda_{i},
\end{aligned}
$$

so

$$
T=\frac{F}{\lambda_{0}-y}=\frac{F / \lambda_{0}}{1-y / \lambda_{0}} .
$$

Hence, the actual response $T$ is a multiple of the basic response (without feedback) $T_{\mathrm{BB}}=T_{0} \equiv F / \lambda_{0}$, and thus

$T=G_{T} T_{0} \quad G_{T}=\frac{1}{1-g_{T}} \quad g_{T} \equiv \frac{y}{\lambda_{0}}=\sum_{i>0} \frac{y_{i}}{\lambda_{0}}=\sum_{i>0} \frac{\left(-\lambda_{i}\right)}{\lambda_{0}}$,

where $G_{T}$ is the climate feedback factor and $g_{T}$ is the gain factor ( $G_{T}$ and $g_{T}$ are dimensionless) (Hansen et al. 1984). The net feedback $y$ is positive, so $g_{T}>0$ and $G>1$. Roe and Baker (2007) note that Hansen et al. (1984) reversed the definition of feedback factor and gain with respect to their meanings in electronics. We are using the terms in the sense of Hansen et al. (1984) and the majority of climate literature.

An alternative way to arrive at this result is to consider the situation as a feedback loop. The imposed forcing $F$ initially causes a response $T_{0}=F / \lambda_{0}$, which augments the effective forcing by $y T_{0}=F y / \lambda_{0}=g_{T} F$ to $\left(1+g_{T}\right) F$. The response to this will be $\left(1+g_{T}\right) T_{0}$, further augmenting the effective forcing to $F+y\left(1+g_{T}\right) T_{0}=(1+$ $\left.g_{T}+g_{T}^{2}\right) F$ and the response to $\left(1+g_{T}+g_{T}^{2}\right) T_{0}$, and so on. Because the feedback processes operate rapidly, the result is the sum of the geometric progression

$$
T=T_{0} \sum_{j=0}^{\infty} g_{T}^{j}=\frac{T_{0}}{1-g_{T}}=G_{T} T_{0},
$$

as before.

In Eq. (2) the terms all have the same form. Each is an independent radiative response of the climate system [although actually they are not entirely independent; e.g., see Randall et al. (2007) and Soden et al. (2008)]. Their net effect $H$ tends to resist the imposed $F$, and they increase together with $T$ until $H$ balances $F$. An analogy to this "resistance" picture is to consider the forcing $F$ as a weight hanging on a spring whose consequent extension is $T$. Then $\lambda$ is the spring constant (tension per unit extension). The blackbody response alone is like a stiff spring with a large spring constant, giving a small extension to support a given weight. Positive feedbacks mean the spring is weaker and extends more.

In Eq. (4) the blackbody response has a special status, which is somewhat arbitrary and artificial, because it is hard to isolate and quantify this effect within the complexity of the climate response to forcing, and it has limited practical relevance. Another drawback with the gain interpretation of heat balance is that the terms are not additive in their effect on $T$, because their sum appears in the denominator of $G$. If the processes are added one by one to Eq. (4), and $T$ is evaluated each time, with $T_{0}$ being the response resulting from all of the processes already considered, a $G=T / T_{0}$ can be assigned to each process; however, owing to the nonlinear combination, these results depend on the order in which the processes are included.

In an unsteady state, $N=F-H \neq 0$. In scenarios of fairly steadily increasing radiative forcing, such as the Special Report on Emissions Scenarios (SRES) A2 scenario (Nakićenović et al. 2000) followed by Friedlingstein et al. (2006), we can approximate $N=\kappa T$, where $\kappa$ is a constant ocean heat uptake efficiency $\left(\mathrm{W} \mathrm{m}^{-2} \mathrm{~K}^{-1}\right.$; Gregory and Mitchell 1997; Dufresne and Bony 2008; Gregory and Forster 2008). This approximation works because the surface climate, which has only a small heat capacity, loses heat into the deeper ocean, which acts as a heat sink in an analogous way to its extra heat loss $\lambda T$ to space (Gregory 2000). It becomes less accurate as the deeper ocean warms up, and it is inapplicable to scenarios in which forcing tends to stabilize and $N \rightarrow 0$. When the approximation holds, Eq. (2) can be replaced by

$$
F=H+N=T(\lambda+\kappa) .
$$


We can write this as

$$
F=\rho T \quad \rho=\lambda+\kappa=\sum \lambda_{i}+\kappa,
$$

where $\rho$ is the climate resistance ( $\mathrm{W} \mathrm{m}{ }^{-2} \mathrm{~K}^{-1}$; Gregory and Forster 2008), and $\kappa(>0)$ can be treated as if it were a negative climate feedback (a positive $\lambda_{i}$ ). Because Eq. (6) has the same form as Eq. (2) $(F=\lambda T)$, the steady-state formalism can be applied to time-dependent simulations in which a constant $\rho$ is a good approximation, by replacing $\lambda$ with $\rho$ in the relevant formulas. In other situations, where $N$ is not proportional to $T$, the formalism cannot be applied.

\section{Coupling of carbon cycle and climate}

The carbon cycle is so called because it involves a flux of carbon through various stores, with the total mass of carbon in the unperturbed system remaining fixed. On centennial time scales, the storage of carbon in rocks and sediments changes little, and the relevant stores are in the atmosphere, the terrestrial biota, the organic carbon in the soil, and in the ocean as dissolved and particulate organic and inorganic compounds and marine biota. Anthropogenic emissions of carbon dioxide from fossil fuels add initially to the carbon content of the atmosphere, but this carbon is subsequently repartitioned among the stores, so the effect is to increase the total mass of carbon in the system. For simplicity we neglect anthropogenic emissions of fossil methane in this argument.

We consider changes of mass of carbon (gigatons of carbon; GtC) in the system relative to its unperturbed preindustrial state. Let $C_{E}$ be the increment resulting from anthropogenic carbon emissions, that is, the time integral of the emitted flux since the start of industrialization. This must be equal to the sum of changes in the stores

$$
C_{E}=C+C_{L}+C_{O},
$$

where $C$ is the change in atmospheric carbon content, $C_{L}$ is the change in carbon storage on land ( $L$ for land), and $C_{O}$ the change in carbon storage in the ocean ( $O$ for ocean).

In the Coupled Climate-Carbon Cycle Model Intercomparison Project (C4MIP), Friedlingstein et al. (2006) carried out an analysis of the changes in the carbon cycle simulated by a set of earth system models in response to the SRES A2 scenario of anthropogenic $\mathrm{CO}_{2}$ emissions (from fossil fuels and land use change) during the twentyfirst century (omitting non- $\mathrm{CO}_{2}$ anthropogenic emissions). Some of the models were AOGCMs coupled to models of the terrestrial biosphere and marine biogeochemistry, and others were earth system models of in- termediate complexity (EMICs). The formalism used by Friedlingstein et al. for their analysis of the results implies various simplifying assumptions, which we now describe, that are not made in the models themselves. Through most of this work we follow these same assumptions, while in section 6 we examine their validity.

Following Friedlingstein et al. (2003), Friedlingstein et al. (2006) assume that the simulated changes in land and ocean stores can be approximated as a linear combination of effects resulting from the change in atmospheric $\mathrm{CO}_{2}$ concentration, and effects resulting from climate change. Thus, $C_{L}=C_{L \beta}+C_{L \gamma}$ and $C_{O}=C_{O \beta}+$ $C_{O \gamma}$, where the final $\beta$ and $\gamma$ subscripts (chosen for consistency with later notation) denote these two classes of effect. We call these classes the concentration (i.e., biogeochemical) and climate effects of $\mathrm{CO}_{2}$. The dominant contribution to $C_{L \beta}$ is carbon fertilization (a positive term, resulting from the stimulation of photosynthesis by elevated $\mathrm{CO}_{2}$ concentration). The term $C_{L \gamma}$ represents the effect of climate change, mainly through temperature and precipitation change, on photosynthesis, plant respiration, soil respiration, and the abundance and distribution of vegetation (terms of both signs, whose sum is found to be negative during the twenty-first century by all C4MIP models). The term $C_{O \beta}$ is principally the increased dissolution of carbon dioxide in the ocean to maintain equilibrium with the atmospheric concentration (a positive term). The term $C_{O \gamma}$ is predominantly the reduction of vertical transport in the ocean resulting from increased stability and reduced solubility in warmer water (both negative); in current models, change in marine biological productivity is relatively unimportant.

For simplicity we aggregate terrestrial and marine stores and write

$$
C_{E}=C+C_{\beta}+C_{\gamma},
$$

where $C_{\beta}=C_{L \beta}+C_{O \beta}$ and $C_{\gamma}=C_{L \gamma}+C_{O \gamma}$. Up to the present time, and in the C4MIP future simulations, an increase of atmospheric $\mathrm{CO}_{2}$ concentration causes the terrestrial and marine stores to take up some carbon $\left(C_{\beta}>0\right)$, but the net climate effect on the stores is to cause carbon to be released $\left(C_{\gamma}<0\right)$. Overall, $C_{\gamma}+$ $C_{\beta}>0 \Rightarrow C<C_{E}$; that is, some of the emitted fossil carbon is stored (see section 4).

Friedlingstein et al. (2006) further assume that $C_{\beta}$ is proportional to the change in atmospheric $\mathrm{CO}_{2}$ content $C$, while $C_{\gamma}$ is proportional to the change in global-mean surface air temperature $T$. As well as linear proportionality, these statements imply instantaneous balance of stores with the current state of the system; there is no explicit dependence on history. Following Friedlingstein 
et al. we write $C_{\beta}=\beta C$ and $C_{\gamma}=\gamma T$, where $\beta$ (GtC $\mathrm{GtC}^{-1}$; i.e., dimensionless) and $\gamma\left(\mathrm{GtC} \mathrm{K}^{-1}\right)$ are constants. (Friedlingstein et al. have separate $\beta$ and $\gamma$ for land and ocean, which we have aggregated, and they express $\beta$ in $\mathrm{GtC} \mathrm{ppm}^{-1}$.) Following the signs of $C_{\beta}$ and $C_{\gamma}, \beta>0$ and $\gamma<0$; hence,

$$
C_{E}=C+\beta C+\gamma T .
$$

For a steady climate, we have Eq. (2), which we rewrite as

$$
F=F_{C}(C)+F_{N}=\lambda T,
$$

where $F_{C}$ is the radiative forcing resulting from an atmospheric $\mathrm{CO}_{2}$ increase, and $F_{N}$ is the sum of all non$\mathrm{CO}_{2}$ forcings, which are not affected by the perturbation to the carbon cycle. For time-dependent change, we can replace $\lambda$ with $\rho$, provided that $F=\rho T$ is a good approximation, which is the case for scenarios of steadily increasing forcing (see section 2), and thus we obtain

$$
F=F_{C}(C)+F_{N}=\rho T .
$$

Equations (9) and (11) constitute a coupled system for time-dependent responses in $T$ and $C$ to imposed changes $F_{N}$ and $C_{E}$.

Anthropogenic land use change, especially deforestation, also affects the partition of carbon among the stores. Its immediate effect is to transfer carbon from $C_{L}$ to $C$ or vice versa; thus, in Eq. (7) we can count land use change in $C_{E}$, even though it is not fossil carbon, if we conserve carbon by making an equal and opposite change to $C_{L}$. The latter cannot be shown in Eq. (8) because land use change is imposed, rather than being a response, so it cannot appear in either $C_{\beta}$ or $C_{\gamma}$. However, the response of the climate and carbon systems to the perturbation in $C$ from land use change will be similar to their response to other $C$ perturbations. It is therefore acceptable to include net emissions from land use change in $C_{E}$ only in Eqs. (8) and (9). However, land use management modifies the nature of the response of the terrestrial carbon system to atmospheric $\mathrm{CO}_{2}$ change and climate change, so it may make $\beta$ and $\gamma$ variable in Eq. (9).

\section{Climate change as carbon cycle feedback}

The radiative forcing $F_{C}$ is a logarithmic function of the atmospheric $\mathrm{CO}_{2}$ content $C_{1}+C$, where $C_{1}$ is a reference value (Shine et al. 1990). For small $C$, following Cox et al. (2006), Friedlingstein et al. (2006), and Scheffer et al. (2006), we approximate it as linear

$$
F_{C}(C)=F_{2 \times} \frac{\ln \left[\left(C_{1}+C\right) / C_{1}\right]}{\ln 2} \simeq \phi C .
$$

For linearization about the present-day $C_{1}=830 \mathrm{GtC}$ (corresponding to $390 \mathrm{ppm}$ by volume) $\phi=F_{2 \times} /\left(C_{1} \ln 2\right)=$ $0.0064 \mathrm{~W} \mathrm{~m}^{-2} \mathrm{GtC}^{-1}\left(0.014 \mathrm{~W} \mathrm{~m}^{-2} \mathrm{ppm}^{-1}\right.$; the addition of $1 \mathrm{GtC}$ to $C$ raises the concentration by $0.47 \mathrm{ppm}$ ). We note that the $\mathrm{CO}_{2}$ perturbations projected for the twenty-first century are not small, so the linearization is not accurate. For a doubling of $\mathrm{CO}_{2}$ from the presentday value, this value for $\phi$ would give $F=5.5 \mathrm{~W} \mathrm{~m}^{-2}$, which is $50 \%$ larger than the intended $F_{2 \times}$. Because C4MIP followed the A2 scenario, we instead linearize the forcing over the range of $\mathrm{CO}_{2}$ concentrations from preindustrial $\left(C_{1}=290 \mathrm{ppm}\right)$ to the end of the twentyfirst century under A2. According to the Bern reference model used by Cubasch et al. (2001), the latter is $C_{2}=$ $840 \mathrm{ppm}$, which is roughly in the middle of the C4MIP models. Hence, $\phi=F_{2 \times} \ln \left(C_{2} / C_{1}\right) / \ln 2 /\left(C_{2}-C_{1}\right)=$ $0.0049 \mathrm{~W} \mathrm{~m}^{-2} \mathrm{GtC}^{-1}\left(0.010 \mathrm{~W} \mathrm{~m}^{-2} \mathrm{ppm}^{-1}\right)$. We should bear in mind that in effect $\phi$ decreases as $C$ rises.

We can solve the simultaneous Eqs. (9) and (11) by eliminating either $C$ or $T$. Eliminating $T$ we get

$$
F_{C}(C)+F_{N}=\rho \frac{C_{E}-(1+\beta) C}{\gamma} .
$$

Using the linear approximation for $F_{C}$ [Eq. (12)] gives

$$
\frac{\gamma}{\rho}\left(\phi C+F_{N}\right)=C_{E}-(1+\beta) C
$$

and hence

$$
C_{E}-\frac{\gamma F_{N}}{\rho}=C\left(1+\beta+\frac{\phi \gamma}{\rho}\right) .
$$

Henceforth, we consider $\mathrm{CO}_{2}$ emissions only, so $F_{N}=0$ (see appendix A for discussion of non- $\mathrm{CO}_{2}$ forcing).

Equation (13) has the resistance form of Eq. (2) $(F=$ $\left.T \sum_{i} \lambda_{i}\right)$, as applied to the carbon system; the imposed forcing $C_{E}$ is opposed by a sum of terms (on the right), each of which is proportional to the change of state $C$. We can write it as

$$
C_{E}=u C \quad u=\sum_{i} u_{i}=1+\beta+u_{\gamma},
$$

where the carbon response parameter $u$ is analogous to the climate feedback parameter $\lambda$, and is the sum of contributions relating to increased storage in the atmosphere $\left(u_{0}=1\right)$, the concentration-carbon response parameter $\beta$, and the climate-carbon response parameter $u_{\gamma}=\phi \gamma / \rho$. Because $\beta>0$ and $\gamma<0$, the concentrationcarbon term is a negative feedback on increase of $C$ and the climate-carbon term a positive feedback [by analogy with Eq. (3), in which negative contributions to $\lambda$ are positive feedbacks on warming]. 
TABLE 3. The upper section of the table shows parameters quantifying climate and carbon responses in the earth system models of C4MIP (Friedlingstein et al. 2006), computed from the values in their Table 3, using formulas from our Table 2. Details of all the models are given by Friedlingstein et al. (2006). The parameters are defined in Table 1, except for $\lambda_{\beta \gamma}$, which is defined in appendix A; $\rho, r_{\beta}, r_{\gamma}$, and $\lambda_{\beta \gamma}$ are in $\mathrm{W} \mathrm{m}^{-2} \mathrm{~K}^{-1} ; \beta, u_{\gamma}, A$, and $g_{\mathrm{CC}}$ are dimensionless; $\gamma$ is in $\mathrm{GtC} \mathrm{K}^{-1}$. SD is the standard deviation across models, and $\mathrm{CV}$ is the coefficient of variation, that is, the ratio of the SD to the magnitude of the mean, expressed as a percentage. Following Eq. (14), $\beta$ can be interpreted as the concentration-carbon response parameter, that is, $u_{\beta} \equiv \beta$, corresponding to the climate-carbon response parameter $u_{\gamma}$. The lower section of the table shows the climate and carbon contributions to the climate response to $\mathrm{CO}_{2}$ emissions, evaluated by combining the climate resistance of CMIP3 AOGCMs with the carbon cycle parameters of the C4MIP models.

\begin{tabular}{|c|c|c|c|c|c|c|c|c|c|}
\hline Model & $\rho$ & $\beta$ & $\gamma$ & $u_{\gamma}$ & $r_{\beta}$ & $r_{\gamma}$ & $A$ & $g_{\mathrm{CC}}$ & $\lambda_{\beta \gamma}$ \\
\hline \multicolumn{10}{|c|}{ C4MIP for both noncarbon feedbacks and carbon cycle feedbacks } \\
\hline HadCM3LC & 1.56 & 0.99 & -201 & -0.62 & 1.54 & -0.98 & 0.73 & 0.31 & -0.49 \\
\hline IPSL-CM2C & 1.59 & 1.50 & -128 & -0.39 & 2.39 & -0.62 & 0.47 & 0.16 & -0.25 \\
\hline IPSL-CM4-LOOP & 1.43 & 1.13 & -36 & -0.12 & 1.62 & -0.17 & 0.50 & 0.06 & -0.08 \\
\hline CSM-1 & 2.72 & 0.94 & -40 & -0.07 & 2.55 & -0.19 & 0.54 & 0.04 & -0.10 \\
\hline MPI & 1.26 & 1.17 & -87 & -0.34 & 1.48 & -0.42 & 0.54 & 0.15 & -0.19 \\
\hline LLNL & 1.52 & 1.74 & -84 & -0.27 & 2.64 & -0.41 & 0.40 & 0.10 & -0.15 \\
\hline FRCGC & 1.75 & 1.13 & -158 & -0.44 & 1.97 & -0.77 & 0.59 & 0.21 & -0.36 \\
\hline UMD & 1.84 & 0.80 & -107 & -0.28 & 1.47 & -0.52 & 0.66 & 0.16 & -0.29 \\
\hline UVic-2.7 & 1.64 & 1.08 & -141 & -0.42 & 1.77 & -0.68 & 0.60 & 0.20 & -0.33 \\
\hline CLIMBER & 1.95 & 0.94 & -79 & -0.20 & 1.83 & -0.38 & 0.57 & 0.10 & -0.20 \\
\hline BERN-CC & 2.24 & 1.36 & -144 & -0.31 & 3.06 & -0.70 & 0.49 & 0.13 & -0.30 \\
\hline Mean & 1.77 & 1.16 & -109 & -0.31 & 2.03 & -0.53 & 0.55 & 0.15 & -0.25 \\
\hline SD & 0.41 & 0.28 & 50 & 0.16 & 0.54 & 0.25 & 0.09 & 0.08 & 0.12 \\
\hline $\mathrm{CV}$ & 23 & 24 & 46 & 49 & 27 & 46 & 17 & 53 & 49 \\
\hline \multicolumn{10}{|c|}{ CMIP3 for noncarbon feedbacks and C4MIP for carbon cycle feedbacks } \\
\hline Mean & 2.05 & - & - & - & 2.38 & -0.53 & - & - & - \\
\hline SD & 0.84 & - & - & - & 0.57 & 0.25 & - & - & - \\
\hline $\mathrm{CV}$ & 41 & - & - & - & 24 & 47 & - & - & - \\
\hline
\end{tabular}

Using $\beta$ and $u_{\gamma}$ we can compare the magnitudes of the concentration-carbon and climate-carbon feedbacks on the carbon system, because they are both dimensionless (whereas $\gamma$ is not). Their values in the C4MIP models of Friedlingstein et al. (2006) are shown in Table 3. On average, the concentration-carbon feedback is about 4 times stronger, and hence dominant. The uncertainty in $\beta$ is nearly twice as large as that in $u_{\gamma}$. The land carbon models of the Lawrence Livermore National Laboratory (LLNL) and the University of Maryland (UMD) have unusual land contributions to $\beta$; LLNL has a particularly large one and UMD a particularly small one, both being outside \pm 2 standard deviations of the C4MIP mean (Denman et al. 2007, their Table 7.4). Excluding these two models reduces the uncertainty in $\beta$ by $25 \%$ to a standard deviation of 0.21 , which still exceeds that of $u_{\gamma}$.

The ratio $u=C_{E} / C$ of the emitted carbon to the increase in atmospheric carbon content can be decomposed, according to Eq. (14), into contributions from the atmosphere, the concentration-carbon response, and the climate-carbon response. In Fig. 1 we show these contributions to $u$, further divided between land and ocean.

A quantity more commonly considered than $u$ is its reciprocal, the airborne fraction,

$$
A=\frac{C}{C_{E}}=\frac{1}{u}=\frac{1}{\sum_{u_{i}}}=\frac{1}{1+\beta+\phi \gamma / \rho} .
$$

As defined here, $A$ is the cumulative airborne fraction, that is, the fraction of all previously emitted $\mathrm{CO}_{2}$ that remains in the atmosphere. We include $A$ in Table 3 , as calculated from other C4MIP parameters. In the C4MIP models, $A$ ranges from 0.40 (LLNL) to 0.73 (Hadley Centre, HadCM3LC). (See section 7 for further discussion of $A$.) It cannot be decomposed linearly into contributions from the individual $u_{i}$, because they are in the denominator of $A$. This is analogous to the treatment of climate sensitivity, in which the individual $\lambda_{i}$ are summed to give the climate feedback parameter $\lambda$; however, because $T \propto 1 / \lambda, T$ cannot be decomposed linearly into contributions from the individual terms.

We can alternatively rewrite Eqs. (14) or (15) as

$$
\begin{aligned}
C & =A C_{E}, \quad A=\frac{1}{1-g_{C}}, \quad \text { and } \\
g_{C} & =-\sum_{i>0} u_{i}=-\beta-u_{\gamma},
\end{aligned}
$$

which has the gain form of Eq. (4), making it apparent that the airborne fraction can also be interpreted as the carbon feedback factor, analogous to $G_{T}$. Here, the basic response (without carbon cycle feedback) of the carbon system to the emission $C_{E}$ is that the atmospheric content $C$ increases by the same amount $C_{E}$. The carbon cycle feedbacks $-u_{i>0}$ modify this basic response. The 


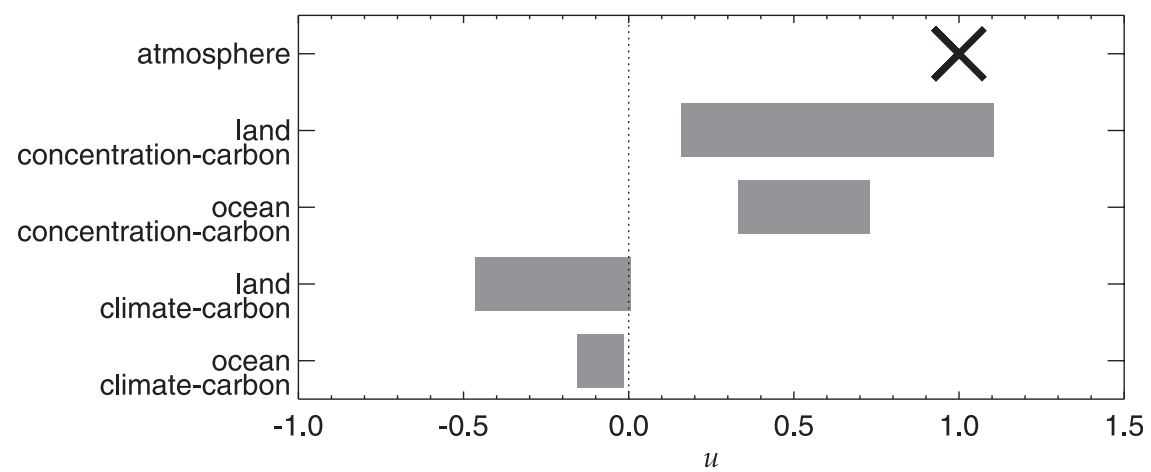

FIG. 1. Comparison of concentration-carbon and climate-carbon responses expressed as contributions to the ratio $C_{E} / C$ of the emitted carbon to the increase in atmospheric carbon content. This ratio is the reciprocal of the airborne fraction. Positive terms indicate positive storage of carbon when $\mathrm{C}$ increases. The land and ocean contributions are as calculated in this paper from the C4MIP models of Friedlingstein et al. (2006). The bars indicate approximate $5 \%-95 \%$ confidence intervals (mean $\pm 1.65 \times \mathrm{SD}$ ). There is no uncertainty in the atmospheric contribution, which is unity by definition.

net feedback is negative, that is, $g_{C}<0$, so $A<1$ and $C$ increases by less than $C_{E}$, unlike the net positive climate feedback $g_{T}>0$, which gives $G_{T}>1$.

Friedlingstein et al. (2006) derive a different gain form of the carbon system change. They include the concentration-carbon response in the basic response of the carbon system to emissions. Without the climatecarbon response, Eq. (14) becomes

$$
C_{E}=C_{n \gamma}(1+\beta) \Rightarrow C_{n \gamma}=\frac{C_{E}}{1+\beta},
$$

where $C_{n \gamma}$ is the corresponding change in atmospheric carbon content; $C_{n \gamma}$ is analogous to $T_{0}=F / \lambda_{0}$ for the basic response of climate change to radiative forcing, with $1+\beta$ in the role of $\lambda_{0}=\lambda_{\mathrm{BB}}$ in Eq. (3). Rewriting Eq. (14) as $C_{E}=C\left[(1+\beta)-\left(-u_{\gamma}\right)\right]$, and comparing with Eq. (3), we see that the climate-carbon response $-u_{\gamma}$ plays the role of $y$. Then, by analogy with Eq. (4), we have

$$
C=G_{\mathrm{CC}} C_{n \gamma} \quad \text { and } \quad G_{\mathrm{CC}}=\frac{1}{1-g_{\mathrm{CC}}},
$$

with

$$
g_{\mathrm{CC}} \equiv-\frac{u_{\gamma}}{1+\beta}=-\frac{\phi \gamma}{\rho(1+\beta)}
$$

being the climate-carbon gain factor, analogous to $y / \lambda_{0}$. Because $\beta>0$ and $\gamma<0$, the gain factor $g_{\mathrm{CC}}>0$; in C4MIP models $g_{\mathrm{CC}}=0.15 \pm 53 \%$ (Table 3; and Table 3 of Friedlingstein et al. 2006). Because $g_{\mathrm{CC}}>0$, $G_{\mathrm{CC}}>1$, meaning that the climate-carbon feedback leads to a greater increase in atmospheric $\mathrm{CO}_{2}$ content for a given emission than would occur if it were not acting. Equations (17) and (18) are equivalent to Eqs. (1) and (7) of Friedlingstein et al. (2006; their $\alpha=\phi / \rho$; see appendix B).

\section{Carbon cycle as climate feedback}

Using the approximation $F_{C}=\phi C$ we can alternatively solve the simultaneous Eqs. (9) and (11) for $T$ by eliminating $C$. For $\mathrm{CO}_{2}$ emissions only, from Eq. (11), we have

$$
\rho T=F_{C}=\phi C,
$$

and Eq. (9) gives

$F_{C}\left(C_{E}\right)=\phi C_{E}=\phi[C(1+\beta)+\gamma T]=\rho T(1+\beta)+\phi \gamma T$,

so

$$
\phi C_{E}=\rho T+\rho \beta T+\phi \gamma T \equiv\left(\rho+r_{\beta}+r_{\gamma}\right) T .
$$

This has the resistance form of Eq. (2) $\left(F=T \sum_{i} \lambda_{i}\right)$ but the left-hand side $\phi C_{E}$ is the radiative forcing of the emitted carbon, not the forcing resulting from the $\mathrm{CO}_{2}$ actually in the atmosphere. We have to express the forcing as emissions because $\mathrm{CO}_{2}$ concentration is a mixture of forcing and response when carbon cycle feedbacks are active. The emissions forcing is balanced by the response of the climate-carbon system, on the right-hand side, which now includes two feedback terms from the carbon cycle, namely, the concentration-carbon feedback parameter $r_{\beta}=\rho \beta$ and the climate-carbon feedback parameter $r_{\gamma}=\phi \gamma$. These new climate feedback parameters are 


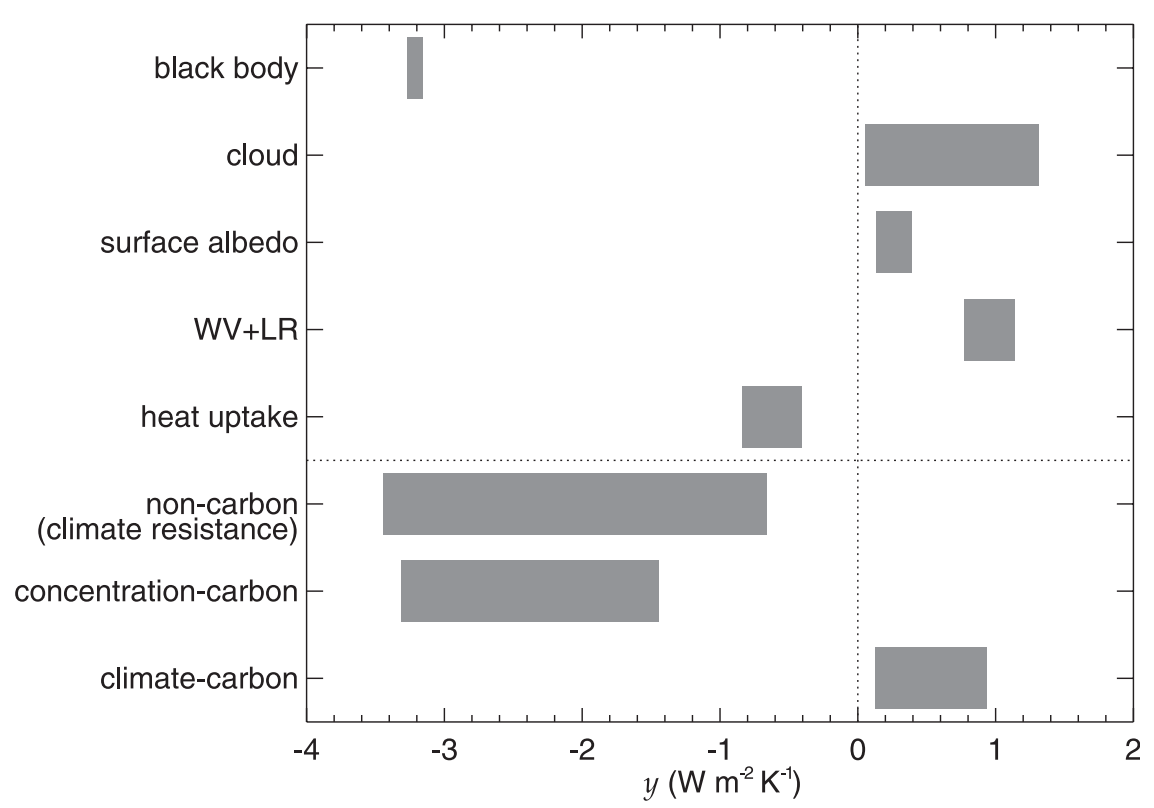

FIG. 2. (top) A comparison of components of climate feedback and ocean heat uptake, and (bottom) a comparison of the combined noncarbon response (the climate resistance, the sum of the terms in the top part) with the carbon cycle feedbacks for forcing resulting from $\mathrm{CO}_{2}$ emissions. The blackbody, cloud, surface albedo, and WV + LR (water vapor and lapse rate) terms are from Soden and Held (2006). The heat uptake term is the ocean heat uptake efficiency $\kappa$ from Gregory and Forster (2008) and the climate resistance is their $\rho$ evaluated from CMIP3 AOGCMs, with its uncertainty amplified by the concentration-carbon feedback as described in the text. The carbon cycle contributions are as calculated in this paper from the C4MIP models of Friedlingstein et al. (2006). We show climate feedback parameters as $-\lambda_{i}$, so that positive terms tend to increase climate warming for a positive forcing; the blackbody response is shown as a negative climate feedback $-\lambda_{\mathrm{BB}}$, and the ocean heat uptake efficiency and climate resistance are likewise negative terms. The bars indicate approximate $5 \%-95 \%$ confidence intervals $($ mean $\pm 1.65 \times \mathrm{SD})$.

just $\rho u_{i}$, where $u_{i}$ are the carbon cycle response parameters of section 4.

The values of $r_{\beta}$ and $r_{\gamma}$ for the C4MIP models are shown in Table 3. In Fig. 2 we compare these carbon cycle feedbacks with atmosphere and surface climate feedbacks (Soden and Held 2006) and ocean heat uptake efficiency (Gregory and Forster 2008). These values for the noncarbon feedbacks represent a wider range of recent GCMs than the C4MIP set of models. Translating the carbon cycle feedbacks into the same terms as climate feedbacks allows us to compare them numerically with each other and with the noncarbon feedbacks.

The concentration-carbon response $r_{\beta}$ is negative, because $\beta>0$. The concentration-carbon response, by sequestering a large fraction of the emitted carbon, is an important feedback that opposes warming, being on average $60 \%$ of the magnitude of the blackbody response. The concentration-carbon feedback is 4 times larger in magnitude than the climate-carbon feedback $r_{\gamma}$, which is positive because $\gamma<0$, and it is of about the same average magnitude as cloud feedback.
The analysis of uncertainty is complicated for forcing by $\mathrm{CO}_{2}$ emissions because $r_{\beta}$ combines the uncertainties in $\rho$ and $\beta$. The $T$ response is determined by the coupled climate-carbon cycle resistance $r_{C 4} \equiv \rho+r_{\beta}+r_{\gamma}$ that appears on the right-hand side of Eq. (20). In the C4MIP models, there is no significant correlation among $\rho, \beta$, and $\gamma$, so we assume their uncertainties to be independent, and hence the variance is

$$
\begin{aligned}
\operatorname{var}\left(r_{C 4}\right)= & \operatorname{var}[\rho(1+\beta)+\phi \gamma]={\overline{(1+\beta)^{2}}}^{2} \operatorname{var}(\rho) \\
& +\bar{\rho}^{2} \operatorname{var}(1+\beta)+\operatorname{var}(1+\beta) \operatorname{var}(\rho)+\operatorname{var}(\phi \gamma) \\
= & (1+\bar{\beta})^{2} \operatorname{var}(\rho)+\bar{\rho}^{2} \operatorname{var}(\beta) \\
& +\operatorname{var}(\beta) \operatorname{var}(\rho)+\phi^{2} \operatorname{var}(\gamma)
\end{aligned}
$$

Thus, the uncertainty (standard deviation) $\sigma\left(r_{C 4}\right)$ combines four independent uncertainties in quadrature. These uncertainties are evaluated in Table 3 using $\rho=$ $2.1 \pm 0.4 \mathrm{~W} \mathrm{~m}^{-2} \mathrm{~K}^{-1}$ (Gregory and Forster 2008) for the climate resistance, based on the AOGCMs of the 
Coupled Model Intercomparison Project Phase 3 (CMIP3) of the World Climate Research Programme (WCRP). The noncarbon feedbacks are reasonably well represented by this $\rho$ during the twenty-first century for emissions scenarios similar to SRES; outside of this range, for instance, in the further future or under stabilization scenarios, it is not valid, and our quantitative conclusions will not apply.

The concentration-carbon feedback magnifies the uncertainty $\sigma(\rho)$ associated with the noncarbon feedbacks (the first term) by $1+\bar{\beta}$, that is, on average $\sigma(\rho)$ is more than doubled. This is because the noncarbon feedbacks determine the magnitude of the warming avoided by the concentration-carbon feedback. The concentrationcarbon feedback also has its own uncertainty $\bar{\rho} \sigma(\beta)$ (the second term). The climate-carbon feedback has an uncertainty $\phi \sigma(\gamma)$ (the fourth term). There is also a relatively small cross-term of $\pm 0.1 \mathrm{~W} \mathrm{~m}^{-2} \mathrm{~K}^{-1}$ resulting from both $\beta$ and $\rho$ (the third term, which appears even though these factors are uncorrelated because they are multiplied together, not added). The absolute uncertainty in $r_{\beta}$ is twice as large as in $r_{\gamma}$. In modeling the climate response to a scenario of $\mathrm{CO}_{2}$ emissions, the concentration-carbon feedback is therefore a greater source of uncertainty than the climate-carbon feedback.

The combination of carbon cycle feedback parameters $r_{\beta}+r_{\gamma}=1.9 \pm 0.6 \mathrm{~W} \mathrm{~m}^{-2} \mathrm{~K}^{-1}$ is of comparable size and uncertainty to the noncarbon climate resistance $\rho=$ $2.1 \pm 0.8 \mathrm{~W} \mathrm{~m}^{-2} \mathrm{~K}^{-1}$, after accounting for combination of uncertainties (Table 3). Huntingford et al. (2009) and Booth et al. (2008, manuscript submitted to Nature), both of whom follow a different approach of varying model parameters, also conclude that for projecting climate change in response to $\mathrm{CO}_{2}$ emissions the uncertainties in the carbon system are of comparable magnitude to those of the climate system.

A further development of the gain formalism (suggested by Scheffer et al. 2006) is to consider the ratio between $T$ for a given $\mathrm{CO}_{2}$ emission with and without the climatecarbon feedback. Without this term, Eq. (20) gives

$$
T_{n \gamma}=\frac{F\left(C_{E}\right)}{\rho+r_{\beta}} .
$$

Rewriting Eq. (20) as $F\left(C_{E}\right)=\left(\rho+r_{\beta}\right) T-\left(-r_{\gamma}\right) T$, and comparing with Eq. (3), we see that $\left(\rho+r_{\beta}\right)$ and $-r_{\gamma}$ play the roles of $\lambda_{0}$ and $y$, respectively, so by analogy with Eq. (4) we define a gain factor

$$
g_{\mathrm{CC}}=-\frac{r_{\gamma}}{\rho+r_{\beta}}=-\frac{\phi_{\gamma}}{\rho(1+\beta)}
$$

and a feedback factor $G_{\mathrm{CC}}=1 /\left(1-g_{\mathrm{CC}}\right)$ for the temperature change.
The formulas for $g_{\mathrm{CC}}$ and $G_{\mathrm{CC}}$ are identical with those of Eqs. (17) and (18). In section 4 we derived them, following Friedlingstein et al. (2006), to quantify the amplification resulting from the climate system of the increase in $C$ following a $\mathrm{CO}_{2}$ emission. Here they quantify the amplification resulting from the carbon system of the increase in $T$ following a $\mathrm{CO}_{2}$ emission. The extra $\mathrm{CO}_{2}$ and extra warming are obviously related, as Friedlingstein et al. point out in their discussion. Both approaches are quantifying the climate-carbon interaction. There is symmetry about whether climate is regarded as a feedback on carbon, or vice versa.

However, we repeat our remark of section 2 that the gain formalism involves an arbitrary choice of basic response. We therefore think it is better to admit that $T$ and $C$ cannot meaningfully be decomposed into additive contributions resulting from different causes, and instead quantify the contributions to the parameters $\rho$ and $u$, which measure resistance to change.

\section{Experimental design and results}

For each model in C4MIP, Friedlingstein et al. (2006) carried out two experiments with the same emissions scenario: one experiment (coupled) in which both the climate system and the carbon system respond to increasing atmospheric $\mathrm{CO}_{2}$; the other (uncoupled) in which only the carbon system responds to $\mathrm{CO}_{2}$, while the climate system experiences the unperturbed control value of $\mathrm{CO}_{2}$. In the former case, both the concentrationcarbon and the climate-carbon responses operate. In the latter case, there is no greenhouse radiative forcing from $\mathrm{CO}_{2}$.

In the experimental design of Hibbard et al. (2007) and Plattner et al. (2008), the scenario is one of concentration rather than emissions. The carbon cycle is simulated, carbon storage on land and ocean evolves, and carbon fluxes are diagnosed, but the atmospheric $\mathrm{CO}_{2}$ concentration is always prescribed, and the emissions necessary to balance the carbon budget can be calculated from the experimental results. According to Eq. (8), the carbon uptake by land and ocean in a coupled experiment following a concentration scenario $C(t)$ is

$$
C_{u}=C_{\beta}+C_{\gamma}=\beta C+\gamma T,
$$

while in an uncoupled experiment (denoted by prime) under the same scenario it is

$$
C_{u}^{\prime}=\beta C,
$$

assuming $T^{\prime}=0$. Hence, $C_{u}-C_{u}^{\prime}=\gamma T$. 
From runs with prescribed concentration, Plattner et al. (2008) evaluate the climate-carbon feedback factor as the ratio $\xi$ of the implied $\mathrm{CO}_{2}$ emissions in the uncoupled and coupled experiments with the same scenario. In general, smaller emissions are implied in the latter (because the climate-carbon response releases $\mathrm{CO}_{2}$ to the atmosphere as the climate warms), so $\xi>1$. Considering Eq. (13) for $\mathrm{CO}_{2}$ only for the two experiments,

$$
C_{E}=(1+\beta+\phi \gamma / \rho) C \text { and } C_{E}^{\prime}=(1+\beta) C,
$$

so

$$
\xi \equiv \frac{C_{E}^{\prime}}{C_{E}}=\left(\frac{C_{E}}{C_{E}^{\prime}}\right)^{-1}=\left(1+\frac{\phi \gamma}{\rho(1+\beta)}\right)^{-1}=\frac{1}{1-g_{\mathrm{CC}}} .
$$

This quantity is thus equal to the climate-carbon feedback factor $G_{C C}$ of Eq. (17). With scenarios of prescribed emissions (so $C_{E}^{\prime}=C_{E}$ ), Denman et al. (2007) evaluate the climate-carbon feedback factor as the ratio of atmospheric $\mathrm{CO}_{2}$ concentrations $C / C^{\prime}$ in the coupled and uncoupled experiments, which is the same as $C / C_{n \gamma}$ of Eq. (17), and hence is also identical to $G_{C C}$.

When we introduced $\beta$ and $\gamma$ to describe the response of the carbon cycle to forcing (section 3), we pointed out that this description implies that the concentrationcarbon and climate-carbon feedbacks can be combined linearly. This can be tested with neither the experimental design of C4MIP nor that of Hibbard et al. (2007). To do so requires an additional experiment, in which $\mathrm{CO}_{2}$ has its radiative effect and forces climate change, but the carbon system experiences the unperturbed control $\mathrm{CO}_{2}$ and the concentration-carbon response is suppressed, which is the reverse of the uncoupled arrangement. With three experiments to distinguish, we need clearer terminology. We will use the term fully coupled for the coupled experiment of Friedlingstein et al. (2006), biogeochemically coupled (indicating that $\mathrm{CO}_{2}$ is biogeochemically active) for their uncoupled, and radiatively coupled for the additional experiment described here. Our naming convention thus indicates which aspects of the system are coupled in the model.

We have carried out all three experiments with the HadCM3LC model (Cox et al. 2001) using a scenario of $\mathrm{CO}_{2}$ increasing at $1 \% \mathrm{yr}^{-1}$, which is a standard idealized experiment for AOGCM studies. Temperature change $T(t)$ in the fully coupled experiment is similar to the sum of the biogeochemically and radiatively coupled experiments (Fig. 3a), with most of $T$ arising from radiative forcing; that is, climate change is largely suppressed in the biogeochemically coupled experiment. However, there is some small climate change in this experiment, which is also noted by Cox et al. (2000). Climate change can be caused by modification to surface properties, such as albedo, arising from changes in the characteristics and distribution of vegetation in response to higher $\mathrm{CO}_{2}$ concentration (Matthews 2007). This is not significant in our biogeochemically coupled experiment. The warming is caused by the physiological response of stomatal closure to elevated $\mathrm{CO}_{2}$ concentrations (Sellers et al. 1996), which effectively gives rise to a small radiative forcing from $\mathrm{CO}_{2}$ (Doutriaux-Boucher et al. 2009; Dong et al. 2009).

Carbon uptake $C_{u}(t)$ in the fully coupled experiment is less than the sum of the other two experiments (Fig. 3b). The difference increases with time; at the end of the experiments, the fully coupled experiment is two-thirds that of the sum. Matthews (2007) followed a similar experimental design, considering only the terrestrial carbon cycle, and in contrast found that the carbon uptake in the fully coupled experiment was greater than the sum of the other two. In either case, the nonlinear combination of the concentration-carbon and climate-carbon responses is an obstacle to their reliable diagnosis, so we advocate that fully, radiatively, and biogeochemically coupled experiments should be carried out with other models.

Friedlingstein et al. (2006) note that the climate-carbon gain factor $g_{\mathrm{CC}} \propto-\gamma /(1+\beta)$ [Eq. (18)] increases with time during their experiments (their Fig. $2 \mathrm{~b}$ ) in all models, by various amounts. They attribute this to the inconstancy of $\gamma$ exhibited by their Figs. 2e,f, which show that the carbon released from land and ocean resulting from climate change rises more rapidly than linearly with $T$, that is, $\gamma$ becomes increasingly negative. In addition, Friedlingstein et al.'s Figs. 2c,d show a weak tendency for the carbon taken up on account of increasing atmospheric $\mathrm{CO}_{2}$ concentration to rise less rapidly than linearly with $C$; that is, $\beta$ decreases.

The inconstancy of $\beta$ and $\gamma$ indicates that the linear formulas $C_{\beta}(C)=\beta C$ and $C_{\gamma}(T)=\gamma T$ are inadequate, but it does not necessarily contradict the assumption that $C_{\beta}$ is a function of $C$ alone and $C_{\gamma}$ of $T$ alone. This can be tested only by trying different scenarios, such that given values of $C$ and $T$ are approached along various trajectories. We have carried out biogeochemically coupled experiments with both HadCM3LC and the IPSL CM4 LOOP (Cadule et al. 2008, manuscript submitted to Proc. Natl. Acad. Sci. USA), with $\mathrm{CO}_{2}$ increasing at $0.5 \%$ and $2 \% \mathrm{yr}^{-1}$ as well as at $1 \% \mathrm{yr}^{-1}$. Comparison of these experiments shows that $C_{\beta}$ is not a unique function of $C$ (Fig. 4); in each model, for a given $C$, uptake is greater with a smaller rate of increase of $\mathrm{CO}_{2}$. This is because the processes of land and ocean uptake are not instantaneous, as would have to be the case for carbon uptake $C_{u}$ to be a function of state. The results also confirm that $C_{\beta}$ 
(a)

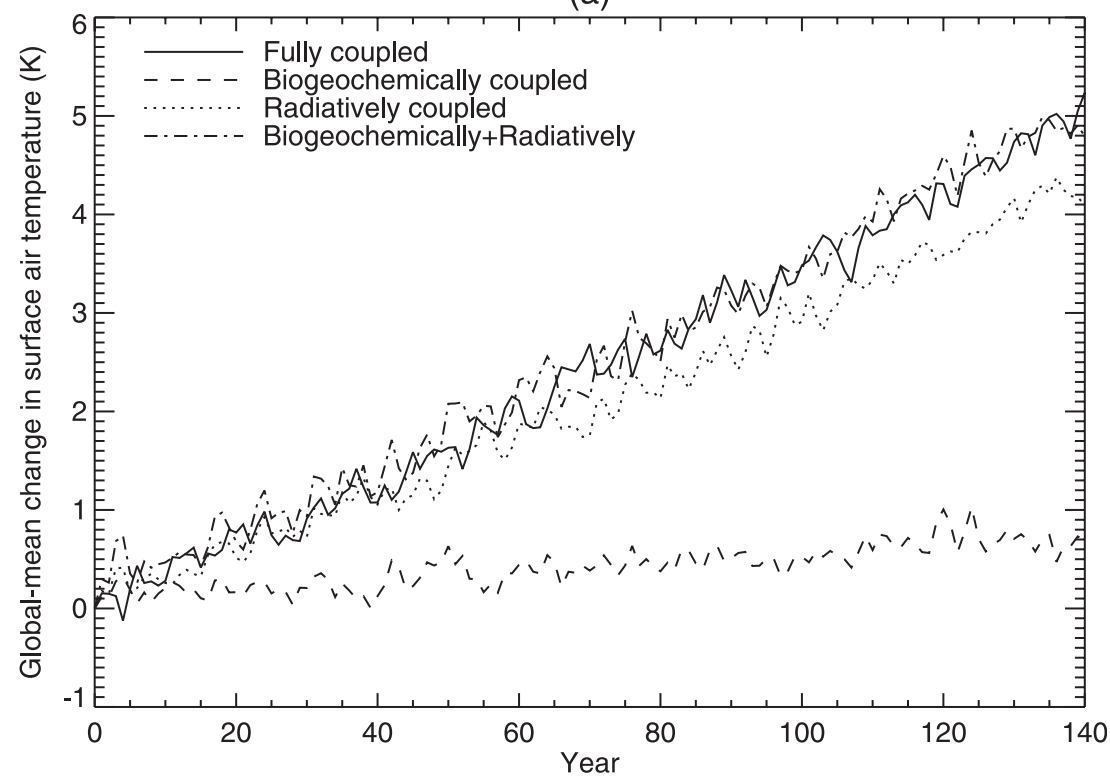

(b)

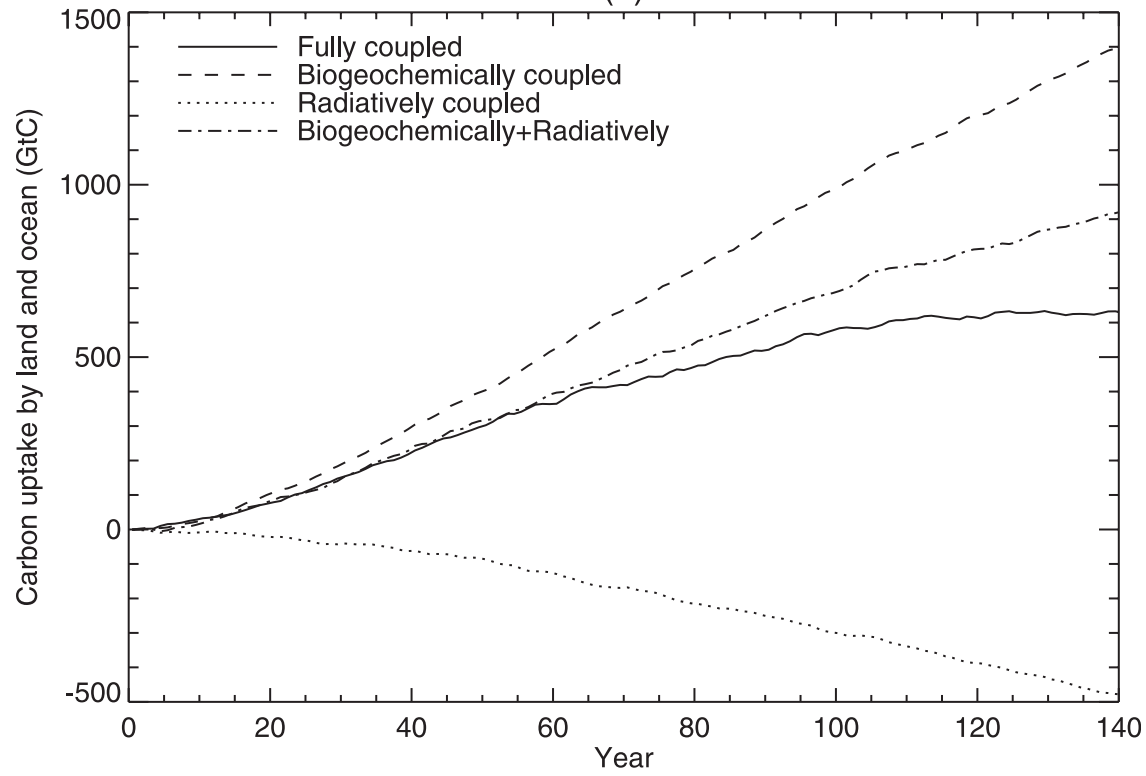

FIG. 3. (a) Global-mean, annual-mean surface air temperature change $T$, and (b) carbon uptake by land and ocean $C_{u}$, as a function of time relative to the control climate in fully, biogeochemically, and radiatively coupled experiments with the HadCM3LC climate-carbon model under a scenario of atmospheric $\mathrm{CO}_{2}$ increasing at $1 \% \mathrm{yr}^{-1}$.

is not proportional to $C$; for a given increment in $C$, uptake becomes smaller as $C$ increases, that is, $\beta$ decreases, as in the C4MIP experiments.

By contrast, $C_{\gamma}$ is more nearly a unique and linear function of $T$ in radiatively coupled experiments (Fig. 5; these experiments were done only with HadCM3LC), although for a given $T$, there is a relatively weak tendency for carbon release to be greater with a smaller rate of increase of $\mathrm{CO}_{2}$. Our result that $C \gamma \propto T$ suggests that a constant $\gamma$ is a reasonable approximation for these scenarios.

From the $1 \%$ scenario we obtain $\gamma=-119 \mathrm{GtC} \mathrm{K}^{-1}$, which is $40 \%$ smaller in magnitude than the value reported by C4MIP for HadCM3LC (Table 3). We can explain this as a consequence of the different methods of estimating $\gamma$, if we assume that $\beta$ and $\gamma$ have qualitatively the same behavior in the C4MIP experiments as we have found in our experiments. In that case, we can write 
(a)

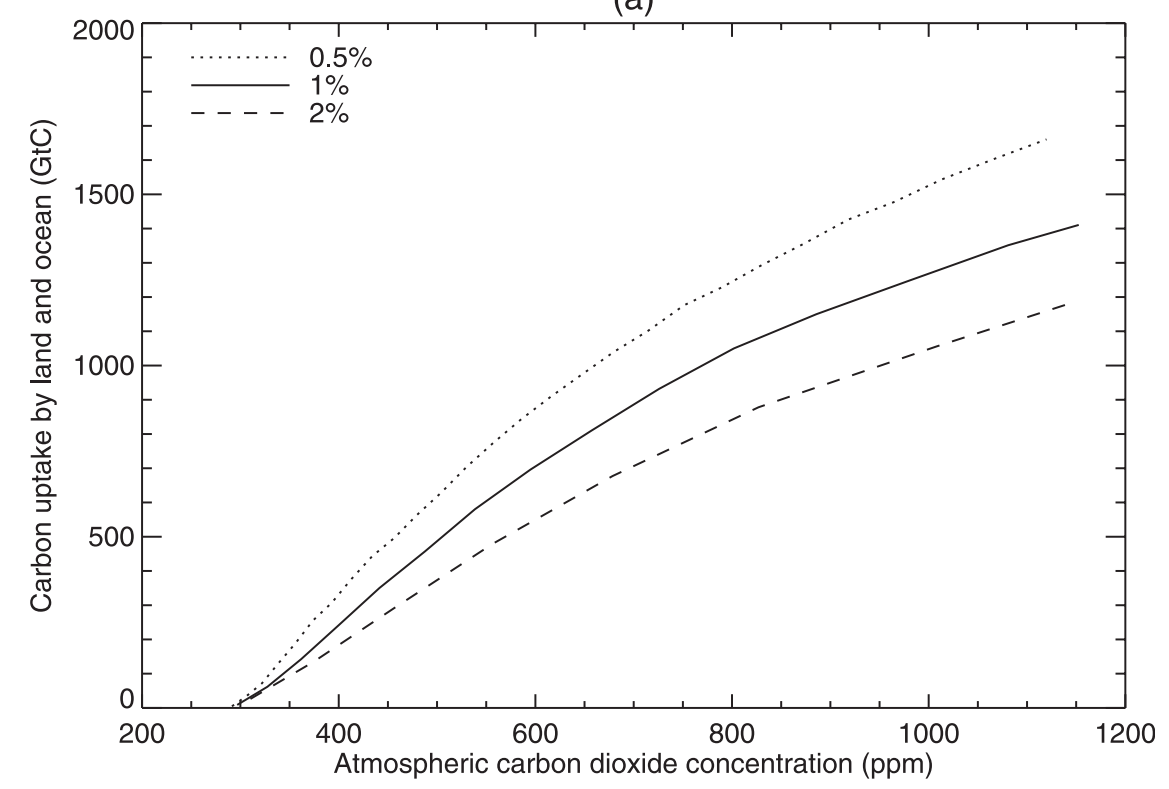

(b)

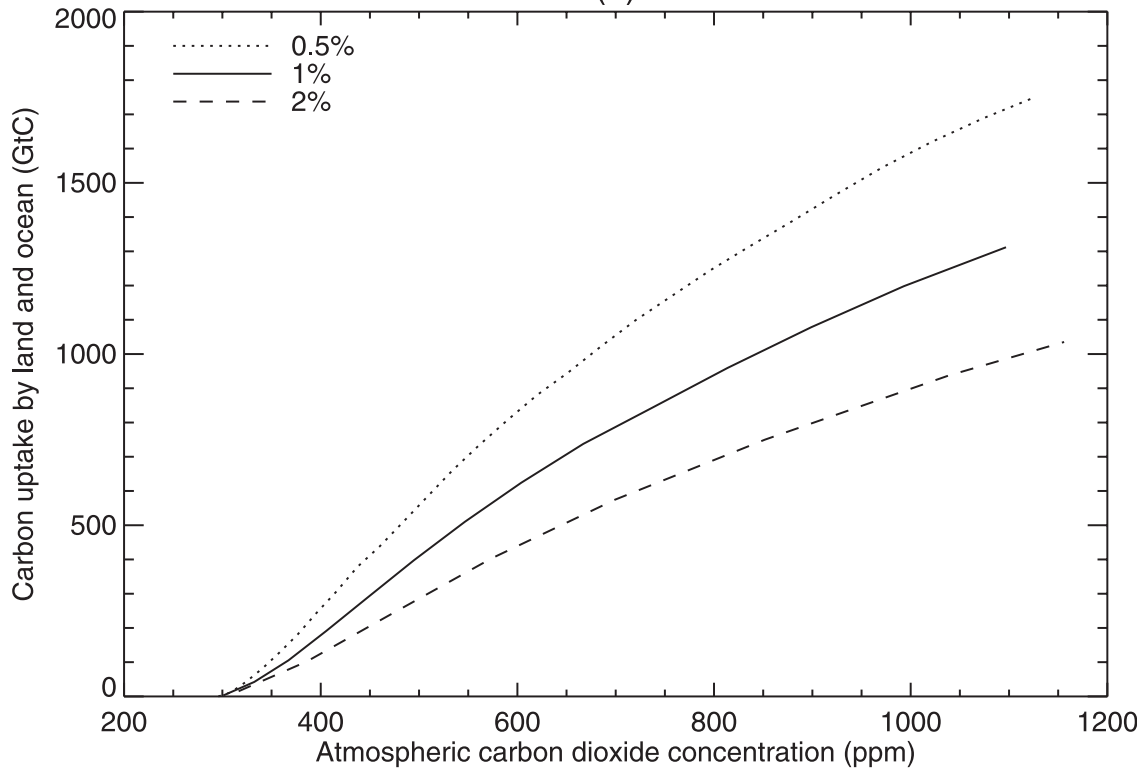

FIG. 4. Carbon uptake by land and ocean relative to the control climate in annual means from biogeochemically coupled experiments with (a) HadCM3LC and (b) IPSL-CM4-LOOP, plotted against the atmospheric $\mathrm{CO}_{2}$ concentration $(1 \mathrm{ppm}=2.1 \mathrm{GtC})$. Results are shown for $\mathrm{CO}_{2}$ increasing at three different rates of $0.5 \%, 1 \%$, and $2 \% \mathrm{yr}^{-1}$.

the carbon uptake in the (fully) coupled C4MIP experiment as $C_{u}=\beta C+\gamma T-\delta_{C}$, where $\delta_{C}$ represents the effect of the nonlinear combination of the concentrationcarbon and climate-carbon responses (Fig. 3b). Because the $\mathrm{CO}_{2}$ emissions are the same in the two C4MIP experiments, but less carbon is taken up in the (fully) coupled experiment, the rate of increase of $C$ in this experiment is larger at all times than the rate of increase of $C^{\prime}$ in the uncoupled (biogeochemically coupled) experiment, so the latter will have $\beta^{\prime}>\beta$ (Fig. 4), and its carbon uptake will be $C_{u}^{\prime}=\beta^{\prime} C^{\prime}=\left(\beta+\delta_{\beta}\right) C^{\prime}$. Friedlingstein et al. (2006) estimate $\gamma$ from the difference in carbon uptake between the two experiments, assuming linearity $\left(\delta_{C}=0\right)$ and constant $\beta\left(\delta_{\beta}=0\right)$. That is, they assume that

$C_{u}-C_{u}^{\prime}=(\beta C+\hat{\gamma} T)-\beta C^{\prime}=\beta\left(C-C^{\prime}\right)+\hat{\gamma} T$, 


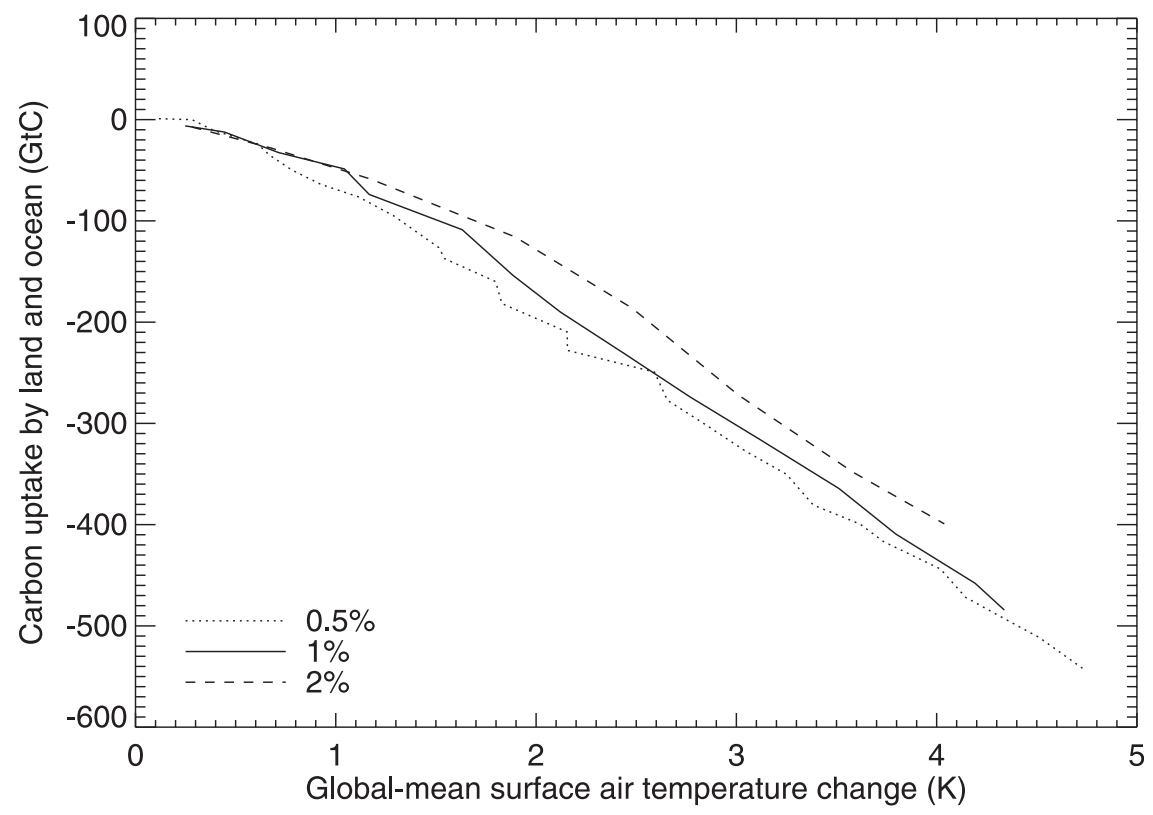

FIG. 5. Carbon uptake (actually release when negative) by land and ocean relative to the control climate in decadal means from radiatively coupled experiments with HadCM3LC, plotted against global-mean surface air temperature change. Results are shown from experiments with $\mathrm{CO}_{2}$, increasing at three different rates of $0.5 \%, 1 \%$, and $2 \% \mathrm{yr}^{-1}$.

where $\hat{\gamma}$ is their estimate of $\gamma$. Therefore,

$$
\hat{\gamma} T=C_{u}-C_{u}^{\prime}-\beta\left(C-C^{\prime}\right)=\gamma T-\delta_{\beta} C^{\prime}-\delta_{C},
$$

so $\hat{\gamma}$ tends to be more negative than $\gamma$ because $\delta_{C}>0$ and $\delta_{\beta}>0$. The C4MIP method attributes to $\hat{\gamma}$ the effects of the nonlinearity and the variable concentration-carbon feedback.

As noted above, there is some climate change in the biogeochemically coupled experiment (Fig. 3a) resulting from the physiological response of vegetation to $\mathrm{CO}_{2}$ and the change in vegetation cover, rather than from $\mathrm{CO}_{2}$ radiative forcing. In the biogeochemically coupled experiment, the carbon uptake is therefore actually $C_{u}^{\prime}=$ $\beta^{\prime} C+\gamma T^{\prime}$. This adds $-\gamma T^{\prime}$ to $\hat{\gamma}$, tending to make it less negative because $\gamma<0$. On the other hand, the estimate of $\beta$ by the C4MIP method $\hat{\beta}=C_{u}^{\prime} / C=\beta^{\prime}+\gamma T^{\prime} / C$ will be less positive than $\beta^{\prime}$.

If the other C4MIP models behave qualitatively like HadCM3LC, there are compensating errors in the equivalent climate feedbacks terms $r_{\beta}$ and $r_{\gamma}$ (section 5 and Table 3) that reduce the magnitude of both, and $r_{\gamma}$ includes a (negative) contribution from their interaction. These complications in the diagnosis of carbon cycle feedbacks from C4MIP results arise because $C_{\gamma}$ can be estimated only as a difference if the radiatively coupled experiment is not carried out. We think that they underline the need to run all three experiments. It is essential that the analysis techniques are not simplified to the point of giving misleading results for the sensitivities of carbon-cycle components.

\section{Metrics of the climate carbon system}

In section 4 we introduced the cumulative airborne fraction $A=1 / u=C / C_{E}$ [Eqs. (14) and (15)], the ratio of the extra carbon content of the atmosphere at time $t$ to the time integral of carbon emissions up to that time. This quantity is a useful metric of the combined effect of the climate-carbon and concentration-carbon feedbacks in determining atmospheric $\mathrm{CO}_{2}$ as a consequence of emissions. For policy making related to mitigation of climate change, it is relevant to consider the allowable rate of emissions $R_{E} \equiv d C_{E} / d t$ that would be consistent with an intended future concentration scenario $C(t)$, as in the experimental design proposed by Hibbard et al. (2007) (see also section 6). Given $C(t), R_{E}(t)$ effectively depends on the incremental airborne fraction $A_{i}$, which we define as the ratio between the rate of increase of atmospheric content and the rate of emission,

$$
A_{i} \equiv \frac{1}{R_{E}} \frac{d C}{d t} .
$$

We can evaluate this by differentiating Eq. (14) to obtain 
(a)

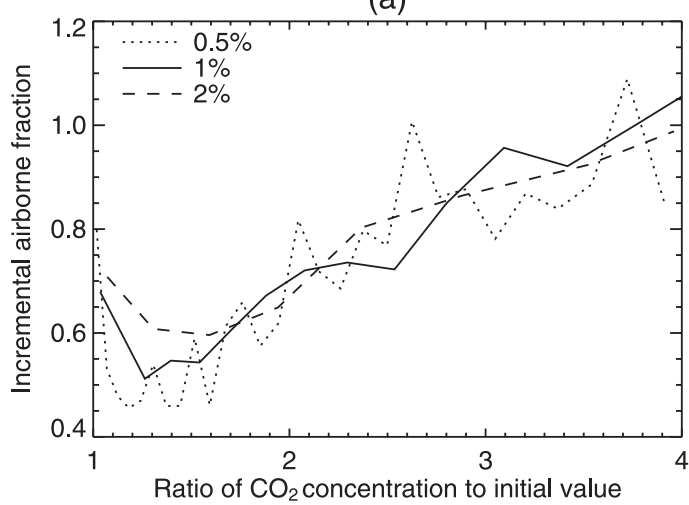

(c)

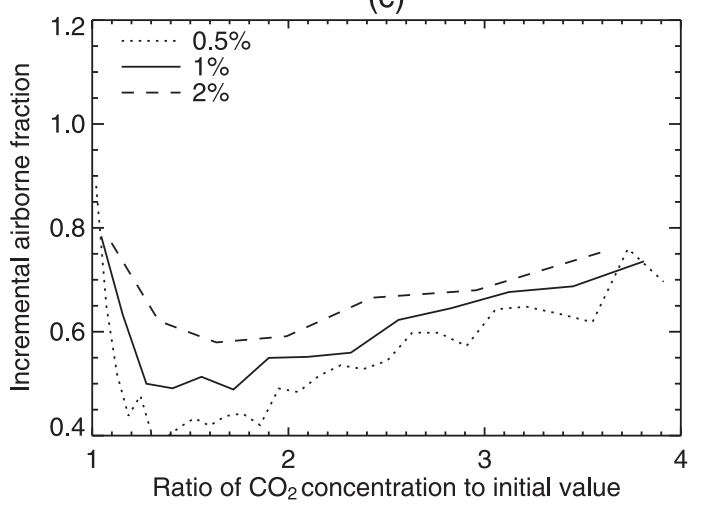

(b)

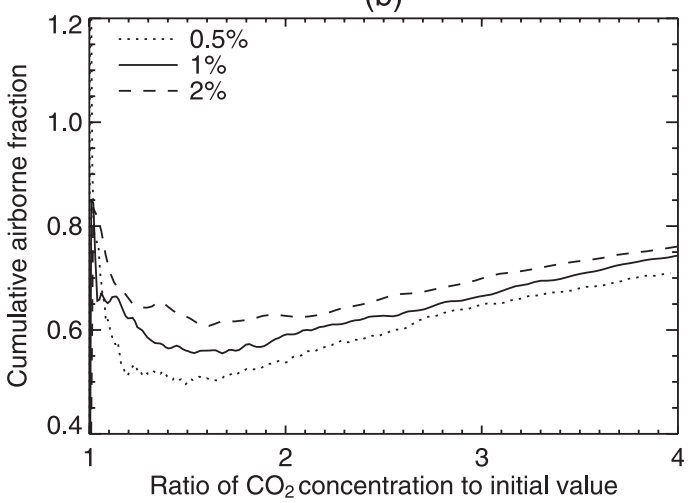

(d)

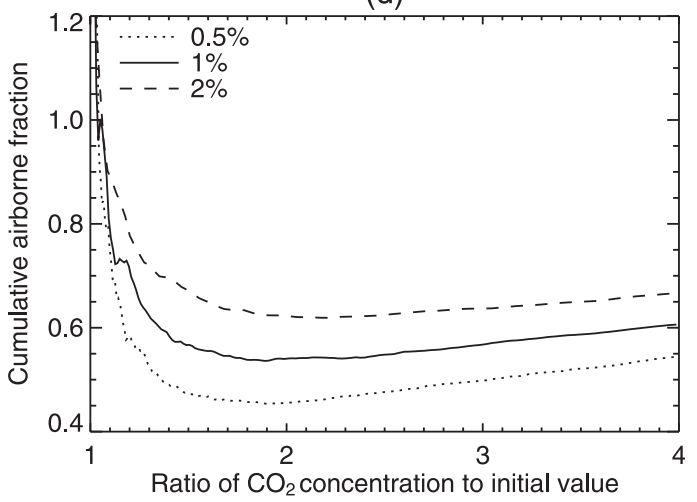

FIG. 6. (a),(c) Incremental and (b),(d) cumulative airborne fraction as a function of atmospheric $\mathrm{CO}_{2}$ concentration in decadal means from fully coupled experiments with (a),(b) HadCM3LC and (c),(d) IPSL-CM4-LOOP. Results are shown from experiments with $\mathrm{CO}_{2}$ increasing at three different rates of $0.5 \%, 1 \%$, and $2 \% \mathrm{yr}^{-1}$.

$$
u \frac{d C}{d t}=\frac{d C_{E}}{d t}=R_{E}
$$

and hence

$$
A_{i}=\frac{1}{u}=A,
$$

that is, the incremental and cumulative airborne fractions are equal. This is a simple consequence of the assumption of constant $\beta$ and $\gamma$, and hence constant $u$ and $A$. Put another way, because

$$
A=\frac{C}{C_{E}}=\frac{\int_{0}^{t} A_{i} R_{E} d t}{\int_{0}^{t} R_{E} d t},
$$

$A=A_{i}$, if $A_{i}$ is constant.

However, unforced interannual variability can lead to large variations in the incremental airborne fraction, causing it to fluctuate around the cumulative airborne fraction (Fig. 7.4b of Denman et al. 2007). Furthermore, as we have seen (section 6), the assumptions of the C4MIP analysis do not hold exactly. Consequently, the incremental and cumulative airborne fractions are neither constant (cf. Denman et al. 2007) nor equal. As $\beta$ decreases, $A$ and $A_{i}$ increase [Eq. (15)]. However, we find that in our fully coupled experiments with HadCM3LC and IPSL-CM4-LOOP, when following different rates of $\mathrm{CO}_{2}$ increase, the incremental airborne fraction is a more scenario-independent function of $\mathrm{CO}_{2}$ (Fig. 6) than of time, though this holds better for HadCM3LC than IPSL-CM4-LOOP. Furthermore, it holds better for $A_{i}$ than $A$, which may indicate that $A_{i}$ is actually more nearly a function of the instantaneous state than $A$ (cf. Boer and Arora 2009). In both models, the airborne fraction is greater at any given $\mathrm{CO}_{2}$ concentration for larger rates of atmospheric $\mathrm{CO}_{2}$ increase, consistent with our earlier observation (section 6) that carbon uptake is less for larger rates of increase.

For a prescribed $C(t)$, there is systematic uncertainty in $A_{i}$, and hence in $R_{E}(t)$. Although the decomposition of the airborne fraction into components from the concentration-carbon and climate-carbon feedbacks is quantitatively only as accurate as the assumptions of the C4MIP analysis, it is very likely that our earlier conclusion 
still holds for the relative sizes of their uncertainties (section 4). Hence, the concentration-carbon feedback dominates the uncertainty in determining the emissions consistent with a given concentration scenario.

If the policy objective is stated in terms of a climate change scenario instead of a concentration scenario, we will want to know the relationship between $T$ and carbon emissions, including carbon cycle uncertainties. The relationship of $T$ to carbon concentrations is often measured by the equilibrium climate sensitivity $F_{2 \times} / \lambda$. Having represented the carbon cycle as contributions to climate feedback $\lambda$, we might think of defining an analogous quantity $F_{2 \times} /\left(\lambda+r_{\beta}+r_{\gamma}\right)$. We might suppose this to be the eventual steady-state warming resulting from the emission of an amount $C_{E 2 \times}$ of carbon equal to the initial carbon content of the atmosphere, because $F_{2 \times}=$ $F\left(C_{E 2 \times}\right)$. Actually, on the long time scale of approach to a steady state, $\beta$ and $\gamma$ are certainly not constant. The eventual steady-state $T$ will probably be zero, because $C$ will return to zero over millennia, resulting from slow processes of marine carbon storage (Denman et al. 2007, their Table 7.3). Possibly there is irreversibility in the system, such that $C$ would approach some nonzero value, but the processes determining this would not be correctly reflected by $\beta$ and $\gamma$ evaluated from projections under SRES scenarios. If the terrestrial carbon cycle alone were considered, disregarding slow processes of carbon storage on land as well as carbon uptake by the ocean, there would be a nonzero steady-state $T$ and $C$.

A metric of time-dependent climate change resulting from change in atmospheric $\mathrm{CO}_{2}$ is the transient climate response TCR $=F_{2 \times} / \rho$, which is $T$ at the time that $\mathrm{CO}_{2}$ reaches twice its initial concentration in a scenario of rising $\mathrm{CO}_{2}$ (see appendix $\mathrm{B}$ ). Including carbon cycle feedbacks, an analogous quantity to the TCR would be the transient climate response to emissions TCRE $\equiv$ $F_{2 \times} /\left(\rho+r_{\beta}+r_{\gamma}\right)$, which is $T$ in response to cumulative carbon emissions of $C_{E 2 \times}$. From Eq. (20), using Eqs. (12) and (15),

$$
\begin{aligned}
\mathrm{TCRE} & =\frac{F_{2 \times}}{\rho(1+\beta+\phi \gamma / \rho)}=\frac{1}{1+\beta+\phi \gamma / \rho} \frac{F\left(C_{E 2 \times}\right)}{\rho} \\
& =A \frac{\phi C_{E 2 \times}}{\rho} .
\end{aligned}
$$

This has an obvious interpretation; $A C_{E 2 \times}$ is the actual increase in $C$ resulting from the emission $C_{E 2 \times}, \phi A C_{E 2 \times}$ is the radiative forcing resulting from this increase in $C$, and TCRE is hence the warming it produces. TCRE thus depends on both noncarbon climate feedbacks measured by $\rho$ (or equivalently TCR) and carbon cycle feedbacks measured by $A$. Furthermore, because TCR $=F_{2 \times} / \rho=$ $\phi C_{E 2 \times} / \rho$, TCRE is simply the product of TCR and $A$.
Matthews et al. (2009) propose a related metric to TCRE, which they call the climate-carbon response. In effect, this quantity is TCRE per gigaton of carbon emitted, TCRE/ $C_{E 2 \times}=\phi A / \rho\left(\mathrm{K} \mathrm{GtC}^{-1}\right)$. It avoids the arbitrary choice of a particular cumulative emission and suggests greater generality. To avoid confusion, we note that the climate-carbon response depends on both the climate-carbon and the concentration-carbon feedback, not just on the former.

TCRE and the climate-carbon response of Matthews et al. (2009) are not constant in general, because none of the factors $\phi, A$, and $\rho$ are really constant. However, Matthews et al. point out that in the C4MIP experiments, while emissions are sustained and $\mathrm{CO}_{2}$ is rising, $\phi A / \rho$ is approximately constant, because $\phi$ declines and $A$ increases as $C$ rises, leading to a remarkably accurate and fortuitous cancellation of these independent variations in time. Moreover, $\phi A / \rho$ is fairly independent of the emissions scenario, because of compensating variations in $A$ and $\rho$; as we found above, $A$ is larger for greater rates of emission, mainly related to terrestrial carbon uptake, but so is $\rho\left(\mathrm{W} \mathrm{m}^{-2} \mathrm{~K}^{-1}\right)$, because ocean heat uptake is less efficient for a faster increase in radiative forcing (Gregory and Forster 2008). Because $\phi A / \rho$ in C4MIP models is therefore nearly time and scenario independent, $T$ is proportional to cumulative carbon emissions (as noted by Van Vuuren et al. 2008; Matthews et al. 2009). However, once emissions cease, $C_{E}$ becomes constant, but $C$ and $T$ slowly fall thereafter (Meehl et al. 2007; Solomon et al. 2009), so $A$ and $T$ per gigaton of carbon emitted must eventually tend to zero.

\section{Summary and conclusions}

Perturbations to the carbon cycle could have a substantial influence on future climate change and atmospheric $\mathrm{CO}_{2}$ concentration, through the concentration-carbon feedback, resulting from the uptake of carbon by land and ocean as a biogeochemical response to the $\mathrm{CO}_{2}$ concentration, and the climate-carbon feedback, resulting from the effect of climate change on carbon fluxes.

In this paper we have demonstrated the similarities between the formalisms used to describe climate change and carbon cycle change. In both cases, the response to forcing can be expressed in two ways, which we call resistance and gain. In the resistance form, a sum of the terms that are individually proportional to the change (in temperature $T$ or $\mathrm{CO}_{2}$ concentration $C$ ) has the net effect of opposing the forcing. We prefer this form, which is nowadays more commonly used in analysis of climate feedback in response to imposed radiative forcing, because it is more suitable for comparing the terms and their uncertainties. For the carbon cycle there is an 
analogous decomposition, which measures its resistance to the imposed emissions. To make the decomposition, we follow the C4MIP intercomparison of coupled climatecarbon cycle models in assuming that the concentrationcarbon response is proportional to $C$, the climate-carbon response is proportional to $T$, and that they can be combined linearly.

In the resistance form, with these assumptions, we show that the effect of the carbon cycle can be regarded as two extra climate feedback terms. This translation allows us to compare these feedbacks with others, and shows that in present models the climate-carbon feedback is positive for warming and is of similar size to the cloud feedback. The concentration-carbon feedback is negative, 4 times larger than the climate-carbon feedback, and more uncertain. The net carbon cycle feedback has a comparable uncertainty to the noncarbon climate response in modeling the climate response to a scenario of $\mathrm{CO}_{2}$ emissions. In an analogous way, climate feedback can be translated into a feedback on the carbon cycle. The concentration-carbon response is the dominant source of uncertainty in the allowable $\mathrm{CO}_{2}$ emissions, which are consistent with a given $\mathrm{CO}_{2}$ concentration scenario.

In the gain form for climate change or carbon cycle change, one of the terms is regarded as the basic response, and the others are treated as feedbacks that add to the imposed forcing and hence amplify the response. The designation of the basic term is somewhat arbitrary and the consequent amplifications (feedback factors) are not additive. The attention that has been given to the uncertainty of the climate-carbon gain may have distracted attention from the uncertainty in the concentrationcarbon response.

We have revisited the design of the experiments and quantities used to measure the carbon cycle response by C4MIP. Using additional experiments with two models, we show that, contrary to the assumptions made above, the concentration-carbon and climate-carbon responses do not combine linearly, and the former in particular is dependent on scenario and time. Consequently, our feedback formalism applies only approximately, though we think it remains useful as an interpretative tool and indicative of the sources of uncertainty. We note that the transient climate response and the climate resistance, used to measure the noncarbon response of the climate system to radiative forcing (Gregory and Forster 2008), are likewise useful despite their not being truly constant. The inconstancy of the climate resistance, and the inaccuracy of the linear approximation for $\mathrm{CO}_{2}$ radiative forcing employed in this analysis (following Scheffer et al. 2006; Friedlingstein et al. 2006), mean that the translation between carbon cycle and noncarbon feed- backs is not exact, but this does not alter our qualitative conclusions.

The inadequacies of the formalism in terms of a constant concentration-carbon $\beta$ parameter and climatecarbon $\gamma$ used here and in previous work motivates further investigation with the aim of finding alternative parameters that are independent and constant in time and across a wide range of scenarios. These parameters should be useful in interpreting the differences among the results from different models, and in estimating results for scenarios that have not been run in the models. Whereas $\beta$ and $\gamma$ relate the carbon storage at any given time to the climate and the $\mathrm{CO}_{2}$ concentration at that time, assuming in effect an instantaneous equilibration of the carbon system, we think that it may be more successful to relate the rate of carbon uptake resulting from various processes to the prevailing state of the system (cf. Cox et al. 2006). Boer and Arora (2009) have tried such an approach to analyze the results from the earth system model of the Canadian Centre for Climate Modelling and Analysis. They assume that the rates of change of carbon stores resulting from the concentrationcarbon and the climate-carbon responses are proportional to $C$ and $T$, respectively. In our notation, they replace Eq. (9) with

$$
R_{E}=\frac{d C_{E}}{d t}=\frac{d C}{d t}-B C-\Gamma T,
$$

where the parameters $-B\left(\mathrm{yr}^{-1}\right)$ and $-\Gamma\left(\mathrm{GtC} \mathrm{yr}^{-1} \mathrm{~K}^{-1}\right)$ appear instead of the C4MIP parameters $\beta$ and $\gamma$. Although their assumptions are different, they reach qualitatively similar conclusions to ours-that the climatecarbon feedback (which they call carbon-temperature) is fairly constant and independent of scenario, whereas the concentration-carbon feedback is neither.

We would make the following recommendations to improve the quantification of the carbon cycle feedbacks in models:

- We propose that three experiments should be carried out for each scenario, which we call fully coupled (C4MIP coupled), biogeochemically coupled (C4MIP uncoupled, in which the $\mathrm{CO}_{2}$ increase has no radiative forcing), and radiatively coupled (in which the $\mathrm{CO}_{2}$ increase has no biogeochemical effect). The radiatively coupled experiment is additional to the C4MIP design. It allows the concentration-carbon and climate-carbon effects to be separated cleanly. Insofar as the response to radiative forcing is independent of the nature of the forcing agent, this experiment can be regarded also as a simulation of the climate and carbon cycle response to non- $\mathrm{CO}_{2}$ greenhouse gas forcing, which has relevance to the analysis of multigas mitigation scenarios. 
- We support the recommendation of Hibbard et al. (2007), adopted in this work and by Plattner et al. (2008), to use scenarios of prescribed concentration rather than emission, because it simplifies the analysis of carbon uptake.

- We advocate that carbon cycle metrics should be evaluated using the scenario of prescribed atmospheric $\mathrm{CO}_{2}$ concentration increasing at $1 \% \mathrm{yr}^{-1}$. This idealized scenario implies a similar magnitude of emissions to typical detailed socioeconomic scenarios for the twenty-first century, and has the advantage of simplicity. It has been a standard for several years for studies of climate response in AOGCMs and is likely to remain in use, whereas the policy-related scenarios are updated more frequently. Adopting the $1 \%$ scenario for carbon cycle studies will facilitate comparison of the climate and carbon feedback terms.

- We suggest that the airborne fraction of $\mathrm{CO}_{2}$ emissions could be used to quantify the net effect upon the carbon cycle of all the climate and carbon feedbacks. As a precisely defined metric for model intercomparison, corresponding to the transient climate response (TCR), we propose the airborne fraction defined as the increase of atmospheric $\mathrm{CO}_{2}$ content relative to the initial state at the time of $2 \times \mathrm{CO}_{2}$, divided by the cumulative $\mathrm{CO}_{2}$ emissions up to that time, in the $1 \%$ scenario.

We believe these recommendations will enable us to gain the maximum benefit from future coupled climatecarbon cycle experiments in order to quantify, understand, and finally reduce uncertainty in modeling carbon cycle feedbacks.

Acknowledgments. We are grateful for discussions with and comments from Peter Cox, Ron Stouffer, Karl Taylor, George Boer, Mark Webb, Mark Ringer, Keith Williams, Olivier Boucher, and Ben Booth, and to Damon Matthews, Gian-Kasper Plattner, and the third referee for their encouraging and constructive reviews. Jonathan Gregory was supported by the National Centre for Atmospheric Science, Climate Division. Work at the Hadley Centre was supported by the Joint DECC, Defra, and MoD Integrated Climate Programme, DECC/Defra (GA01101), MoD (CBC/2B/0417_Annex C5). Work at IPSL was supported by the ENSEMBLES project funded by the European Commission (GOCE-CT-2003505539). Computer time was provided by CEA and CNRS.

\section{APPENDIX A}

\section{Non- $\mathrm{CO}_{2}$ Radiative Forcing}

In this paper, we have confined our attention to $\mathrm{CO}_{2}$ forcing, for simplicity and because it is the dominant forcing in scenarios for the twenty-first century. Here, we consider non- $\mathrm{CO}_{2}$ forcing.

If there are no $\mathrm{CO}_{2}$ emissions, Eq. (9) gives

$$
C=-\frac{\gamma}{1+\beta} T,
$$

that is, $C$ and $T$ vary together (Scheffer et al. 2006; Cox and Jones 2008). From Eq. (11), we have

$$
\lambda T-F_{N}=F_{C}=\phi C,
$$

so

$$
F_{N}=T\left(\lambda+\lambda_{\beta \gamma}\right) \quad \lambda_{\beta \gamma} \equiv \frac{\phi \gamma}{1+\beta},
$$

which has the resistance form of Eq. (2) $\left(F=T \sum_{i} \lambda_{i}\right)$. Hence, the carbon cycle modifies the climate response to a non- $\mathrm{CO}_{2}$ forcing by introducing the extra climate feedback term $\lambda_{\beta \gamma}$. By analogy with Eq. (3), we see that this is a positive feedback on climate change because $\gamma<0 \Rightarrow \lambda_{\beta \gamma}<0$. It is tabulated for C4MIP models in Table 3; it has a similar size and uncertainty to the surface albedo feedback.

\section{APPENDIX B}

\section{Relationship of $C$ and $T$ under $\mathrm{CO}_{2}$ forcing}

Equation (19) shows that $T=(\phi / \rho) C$ in scenarios of steadily increasing $\mathrm{CO}_{2}$ forcing with no non- $\mathrm{CO}_{2}$ forcing; Friedlingstein et al. (2006) call the ratio $\alpha=T / C=$ $\phi / \rho$ the linear transient climate sensitivity to $\mathrm{CO}_{2}$. This quantity is related to the transient climate response (TCR; Cubasch et al. 2001), which is defined as $T$ at the time of doubled $\mathrm{CO}_{2}$ in an experiment in which $\mathrm{CO}_{2}$ increases at $1 \% \mathrm{yr}^{-1}$ compounded; because $F=\rho T$ is a good approximation in this scenario, TCR $=F_{2 \times} / \rho$ (Gregory and Forster 2008). Hence,

$$
\alpha=\frac{\phi}{\rho}=\frac{F_{2 \times}}{C_{1} \ln 2} \frac{\mathrm{TCR}}{F_{2 \times}}=\frac{\mathrm{TCR}}{C_{1} \ln 2} .
$$

\section{REFERENCES}

Boer, G. J., and V. Arora, 2009: Temperature and concentration feedbacks in the carbon cycle. Geophys. Res. Lett., 36, L02704, doi:10.1029/2008GL036220.

Colman, R., 2003: A comparison of climate feedbacks in general circulation models. Climate Dyn., 20, 865-873.

Cox, P. M., and C. D. Jones, 2008: Illuminating the modern dance of climate and $\mathrm{CO}_{2}$. Science, 321, 1642-1644, doi:10.1126/ science. 1158907 . 
R. A. Betts, C. D. Jones, S. A. Spall, and I. J. Totterdell, 2000: Acceleration of global warming due to carbon-cycle feedbacks in a coupled climate model. Nature, 408, 184-187.

,,,---- , and,- 2001 : Modelling vegetation and the carbon cycle as interactive elements of the climate system. Meteorology at the Millennium, R. Pearce, Ed., Academic Press, 259-279.

- C. Huntingford, and C. D. Jones, 2006: Conditions for sink-tosource transitions and runwaway feedbacks from the land carboncycle. Avoiding Dangerous Climate Change, H. J. Schellnhuber et al., Eds., Cambridge University Press, 155-161.

Cubasch, U., and Coauthors, 2001: Projections of future climate change. Climate Change 2001: The Scientific Basis, J. T. Houghton et al., Eds., Cambridge University Press, 525-582.

Denman, K. L., and Coauthors, 2007: Couplings between changes in the climate system and biogeochemistry. Climate Change 2007: The Physical Science Basis, S. Solomon et al., Eds., Cambridge University Press, 499-507.

Dong, B., J. M. Gregory, and R. Sutton, 2009: Understanding landsea warming contrast in response to increasing greenhouse gases. Part I: Transient adjustment. J. Climate, 22, 30793097.

Doutriaux-Boucher, M., M. J. Webb, J. M. Gregory, and O. Boucher, 2009: Carbon dioxide induced stomatal closure increases radiative forcing via a rapid reduction in low cloud. Geophys. Res. Lett., 36, L02703, doi:10.1029/2008GL036273.

Dufresne, J.-L., and S. Bony, 2008: An assessment of the primary sources of spread of global warming estimates from coupled atmosphere-ocean models. J. Climate, 21, 5135-5144.

Forster, P. M. de F., and K. E. Taylor, 2006: Climate forcings and climate sensitivities diagnosed from coupled climate model integrations. J. Climate, 19, 6181-6194.

Friedlingstein, P., J. L. Dufresne, P. M. Cox, and P. Rayner, 2003: How positive is the feedback between climate change and the carbon cycle? Tellus, 55B, 692-700.

_ sis: Results from the C4MIP model intercomparison. J. Climate, 19, 3337-3353.

Gregory, J. M., 2000: Vertical heat transports in the ocean and their effect on time-dependent climate change. Climate Dyn., 16, 501-515.

— , and J. F. B. Mitchell, 1997: The climate response to $\mathrm{CO}_{2}$ of the Hadley Centre coupled AOGCM with and without flux adjustment. Geophys. Res. Lett., 24, 1943-1946.

— and P. M. Forster, 2008: Transient climate response estimated from radiative forcing and observed temperature change. J. Geophys. Res., 113, D23105, doi:10.1029/2008JD010405.

— and M. J. Webb, 2008: Tropospheric adjustment induces a cloud component in $\mathrm{CO}_{2}$ forcing. J. Climate, 21, 58-71.

- , and Coauthors, 2004: A new method for diagnosing radiative forcing and climate sensitivity. Geophys. Res. Lett., 31, L03205, doi:10.1029/2003GL018747.

Hansen, J. E., A. Lacis, D. Rind, G. Russell, P. Stone, I. Fung, M. Ruedy, and J. Lerner, 1984: Climate sensitivity: Analysis of feedback mechanisms. Climate Processes and Climate Sensitivity, J. E. Hansen and T. Takahashi, Eds., Amer. Geophys. Union, 130-163.
Hibbard, K. A., G. A. Meehl, P. M. Cox, and P. Friedlingstein, 2007: A strategy for climate change stabilization experiments. Eos, Trans. Amer. Geophys. Union, 88, doi:10.1029/2007EO200002.

Huntingford, C., J. A. Lowe, B. B. B. Booth, C. D. Jones, G. R. Harris, L. K. Gohar, and P. Meir, 2009: Contributions of carbon cycle uncertainty to future climate projection spread. Tellus, 61B, 355-360, doi:10.1111/j.1600-0889.2009.00414.x.

Matthews, H. D., 2007: Implications of $\mathrm{CO}_{2}$ fertilization for future climate change in a coupled climate-carbon model. Global Change Biol., 13, 1068-1078, doi:10.1111/j.1365-2486.2007. 01343.x.

— N. Gillett, P. A. Stott, and K. Zickfeld, 2009: The proportionality of global warming to cumulative carbon emissions. Nature, 459, 829-832.

Meehl, G. A., and Coauthors, 2007: Global climate projections. Climate Change 2007: The Physical Science Basis, S. Solomon et al., Eds., Cambridge University Press, 747-845.

Myhre, G., E. J. Highwood, K. P. Shine, and F. Stordal, 1998: New estimates of radiative forcing due to well mixed greenhouse gases. Geophys. Res. Lett., 25, 2715-2718.

Nakićenović, N., and Coauthors, 2000: Emissions Scenarios. Cambridge University Press, 599 pp.

Plattner, G.-K., and Coauthors, 2008: Long-term climate commitments projected with climate-carbon cycle models. J. Climate, 21, 2721-2751.

Randall, D. A., and Coauthors, 2007: Climate models and their evaluation. Climate Change 2007: The Physical Science Basis, J. T. Houghton et al., Eds., Cambridge University Press, 589-662.

Roe, G., 2009: Feedbacks, timescales, and seeing red. Annu. Rev. Earth Planet. Sci., 37, 93-115, doi:10.1146/annurev.earth.061008. 134734.

— and M. B. Baker, 2007: Why is climate sensitivity so unpredictable? Science, 318, 629-632, doi:10.1126/science.1144735.

Scheffer, M., V. Brovkin, and P. M. Cox, 2006: Positive feedback between global warming and atmospheric $\mathrm{CO}_{2}$ concentration inferred from past climate change. Geophys. Res. Lett., 33, L10702, doi:10.1029/2005GL025044.

Sellers, P. J., and Coauthors, 1996: Comparison of radiative and physiological effects of doubled atmospheric $\mathrm{CO}_{2}$ on climate. Science, 271, 1402-1406.

Shine, K. P., R. G. Derwent, D. J. Wuebbles, and J.-J. Morcrette, 1990: Radiative forcing of climate. Climate Change: The IPCC Scientific Assessment, J. T. Houghton, G. J. Jenkins, and J. J. Ephraums, Eds., Cambridge University Press, 45-68.

Soden, B. J., and I. M. Held, 2006: An assessment of climate feedbacks in coupled ocean-atmosphere models. J. Climate, 19, 3354-3360.

,,-- R. Colman, K. M. Shell, J. T. Kiehl, and C. A. Shields, 2008: Quantifying climate feedbacks using radiative kernels. J. Climate, 21, 3504-3520.

Solomon, S., G.-K. Plattner, R. Knutti, and P. Friedlingstein, 2009: Irreversible climate change due to carbon dioxide emissions. Proc. Natl. Acad. Sci. USA, 106, 1704-1709, doi:10.1073/ pnas.0812721106.

Van Vuuren, D. P., and Coauthors, 2008: Temperature increase of 21st century mitigation scenarios. Proc. Natl. Acad. Sci. USA, 105, 15 258-15 262, doi:10.1073/pnas.0711129105. 